\title{
Is trading behavior stable across contexts? Evidence from style and multi-style investors
}

\author{
D. W. BLACKBURN $\dagger$, W. N. GOETZMANN $\ddagger$ and A. D. UKHOV §*
}

Submitted to Quantitative Finance November 20, 2012

Published 2014 in Volume. 14, No. 4, 605-627

†Graduate School of Business

Fordham University

113 West 60th Street 6th floor

New York, NY 10023

$\ddagger$ Yale School of Management

Yale University

135 Prospect St.

New Haven, CT 06520

$\S$ Cornell University

465C Statler Hall

Ithaca, NY 14853

*Corresponding author. Email: andrey.ukhov@gmail.com 


\begin{abstract}
In this paper we study priming of identity within the context of inherent vs. contextual financial decision making. We use a sample of individual trading accounts in equity-style funds taken from one fund family to test the hypothesis that trading styles are inherent vs. contextual. Our sample contains investors who invest either in a growth fund, a value fund, or both. We document behavioral differences between growth fund investors and value fund investors. We find that their trades depend on past returns in different ways: growth fund investors tend towards momentum trading and value fund investors tend towards contrarian trading. These differences may be due to inherent clientele characteristics, including beliefs about market prices, specific personality traits and cognitive strategies that cause them to self-select into one or the other style. We use a sample of investors that trade in both types of funds to test this proposition. Consistent with the contextual hypothesis, we find that investors who hold both types of funds trade growth fund shares differently than value fund shares.
\end{abstract}

Keywords: Behavioral finance; Investor behavior; Mutual funds; trading strategies

JEL Classification: D8, D9, E2, E21, G1 


\section{Is trading behavior stable across contexts? Evidence from style and multi-style investors}

\section{Introduction}

There is considerable evidence of behavioral differences in financial decision-making. ${ }^{1}$ In this paper we examine the extent to which trading behavior may depend on context, where the context is established by the type or category of asset. ${ }^{2}$ For example, an investor who exhibits risk-seeking behavior in his or her equity account may be very conservative in the management of a fixed income or cash account. An investor who has a tendency towards the disposition effect for stocks purchased for speculative intent may not exhibit that behavior for stocks purchased for yield. This question is relevant to the issue of whether behavioral tendencies are inherent or whether they may be primed, or even be a function of the classification of the asset itself.

We use a sample of individual trading accounts in equity-style funds taken from one fund family to test the hypothesis that trading styles are inherent vs. contextual. Our sample contains investors who invest either in a growth fund, a value fund, or both. We document behavioral differences between growth fund investors and value fund investors. We find that their trades depend on past returns in different ways: growth fund investors tend towards momentum trading and value fund investors tend towards contrarian trading. These differences may be due to inherent clientele characteristics. For example, style funds may attract investors who have a specific philosophy about market prices, or specific personality traits and cognitive strategies that cause them to self-select into one or the other style. We use a sample of investors that trade in both funds to test this proposition. Consistent with the contextual hypothesis, we find that investors trade their growth fund shares differently than their value fund shares.

\subsection{Background}

\footnotetext{
${ }^{1}$ See Barber and Odean (2001), Grinblatt and Keloharju (2001), Goetzmann and Massa (2002, 2003), Kaniel et al. (2008), and Deaves et al. (2009).

${ }^{2}$ A general discussion of context-dependent financial decision making is contained in Slovic (1972), Trimpop (1994), and Shiller (1998).
} 
Past research has examined how personal attributes such as risk aversion, age, religion and gender can explain differences in investor decision-making. ${ }^{3}$ There is also considerable evidence that decisionmaking under uncertainty changes according to context. Classic studies by Kahneman and Tversky (1979) show that contextual framing of identical payoffs can alter the typical response. Experimental evidence suggests that priming can affect risk-taking behavior. ${ }^{4}$ Self-construal, or identification with a particular group, appears to be a significant means by which behavioral shifts are induced. Bargh et al. (1996) established that priming identification with certain stereotypes affects behavior. Benjamin et al. (2010a,b, 2012) show that priming ethnic and religious identity influences economic choice. Mandel (2003) and Hamilton and Biehal (2005) show that risk aversion is susceptible to priming subjects' self-construal in the independent vs. interdependent dimension. In contrast to the abundant experimental evidence on inherent and contextual influences on economic decision-making, there is less evidence about crosssectional investor behavior drawn from actual market context. In this paper we use a sample of individual investor mutual fund accounts to study factors influencing the heterogeneity of investor trading and to examine evidence regarding inherent vs. contextual factors.

This study is related in general to research on attitudes toward risk. Many attempts have been made in the decisions- under-uncertainty literature to understand the underlying factors in risk taking. ${ }^{5}$ Personality theories focus on characteristics or traits of the individual, such as age or gender or cognitive ability, and are largely based on biological trait models. ${ }^{6}$ In terms of asset pricing theory, this view is consistent with the modeling of individuals by means of a utility function that captures relevant systematic differences in behavior (e.g. risk aversion). Situation-dependent theories have attempted to

\footnotetext{
${ }^{3}$ For example, in a well-known study, Barber and Odean (2001) find that men trade more than women. See also Deaves et al. (2009) for a discussion of gender, overconfidence, and trading. Many papers focus on the connection between investor-level attributes and investor trading, including Dorn and Huberman (2005), Feng and Seasholes (2005), and Christiansen et al. (2008). In an experimental study, Dohmen et al. (2010) find that risk aversion varies systematically with cognitive ability.

${ }^{4}$ See Gilad and Kliger (2008).

${ }^{5}$ See the excellent review of Trimpop (1994).

${ }^{6}$ The first of the modern personality theories was developed by Pavlov (1927/1960). In canonical asset pricing theories investors are characterized by agent-specific attributes (such as risk preferences) and investors treat all assets in the investment opportunity set similarly (see, for example, Feldman (2002) and Bossaerts and Plott (2004)).
} 
identify situational processes and moderating variables. Mental accounting and loss aversion are examples of such theories. ${ }^{7}$ Whereas personality theories argue that individuals make decisions because of their own internal characteristics, the situation-dependent theories argue that individuals make decisions based on the characteristics of the external situation. For example, investors may believe that the return generating process for each style is different and therefore a different approach to trading is required. Despite theory which argues for a single pricing kernel, this view is more in alignment with behavioral theories in that agents categorize assets into distinct groups based on some common characteristic and then treat each group as if they are fundamentally different. In sum, while personality theories and situation-dependent theories are both valid and important sub-factors in the concept of risk, the evidence linking the two has been elusive.

\subsection{Our approach}

To derive testable hypotheses about inherent vs. contextual behavior, we propose a mechanism based on priming of identity. We assume that investors who own and trade shares in a particular fund identify with the investment philosophy governing the management of that fund. For example, an investor in a value fund identifies himself or herself as a value investor: one who believes in an intrinsic economic value to an asset around which the market price fluctuates due to market imperfections. By the same token, a growth fund investor is assumed to identify with the growth investment philosophy: identification of stocks with high potential for future growth based on earnings and past trends. Under this assumption, an investor in a value fund would exhibit contrarian investment behavior: selling shares after prices rose above some fundamental value and buying when they dropped below. On the other hand, an investor in a growth fund would behave like a momentum investor, buying shares exhibiting positive appreciation and selling them after a significant drop. Presumably, investors self-select into these style funds based on personal beliefs or traits.

\footnotetext{
7 See Thaler (1980, 1985), Thaler and Johnson (1990), Barberis and Huang (2001), and Haigh and List (2005) and references therein.
} 
The contextual mechanism we propose relies on the potential for one or the other investment style to be made salient in an investor who holds both types of funds. Chiao et al. (2006) and Benjamin et al. (2007, 2010b) demonstrate success in priming different group associations in mixed-race subjects. This suggests that a single subject can maintain a latent identification with multiple groups, and that priming can make one of multiple identities salient for decision-making. In other words, an investor holding shares in both growth and value funds may identify with the philosophy and subscribe to the implied trading behavior of both styles at once, even though, in certain contexts, this would imply opposite responses to past price trends. In fact, growth and value investing need not be incompatible; they may be appropriate investment styles for different categories of stocks, for example.

We propose that investors think of their growth and value funds as separate strategies and employ different trading rules depending on which of the two they trade. This may be facilitated by a subliminal priming or framing, or it may be conscious and based on a belief about the efficacy of employing different strategies for different categories of investment. Although we document evidence of contextual decision-making, we do not distinguish between conscious vs. unconscious determinants of behavior, as we cannot control or observe the precise context in which the decisions are made.

This paper obtains three main results. First, we analyze trading decisions at an individual level with respect to investments of different, clearly defined, characteristics — growth and value investments. Using individual trade data, we demonstrate that investors who specialize in different classes of assets (growth or value funds) tend to follow different trading rules. Value investors tend to be contrarian buyers (buying after price declines), while growth investors tend to be momentum buyers (buying after price increases). This is our first contribution. While it is important to understand whether trading decisions depend on the type of asset being traded, the prior literature on trading behavior maintained a latent assumption that trading decisions are independent of the type of asset being traded. Our results suggest that it may be important to consider the interaction between the type (the style) of asset being traded and investor decisions. The results remain after numerous robustness checks. 
We classify the investor as a momentum (contrarian) buyer if the number of purchases occurring on days following a positive (negative) return signal is significantly greater than that expected assuming a random distribution of trades. Following Goetzmann and Massa (2002), we use a binomial distribution to determine whether the number of trades following a particular strategy is greater than expected if the investor traded randomly. This statistic is equivalent to a 'backwards-looking' Henriksson and Merton (1981) timing test, and thus its properties are well-understood. This approach to investor classification takes into account market conditions, because it includes the probability of observing a particular return signal.

Second, having established that growth-only and value-only investors display differences in their propensities to trade, we study individual investors who trade both value and growth securities. We find that multi-style investors appear to adopt different trading strategies depending on the characteristics of the asset being traded. These findings are consistent with the hypothesis that the trading style of an individual is not necessarily an inter-temporally consistent characteristic independent of context, but instead may be influenced by the characteristics of the investment.

Third, we consider many different trading signals in order to allow for differences in horizon across individuals. We find that individuals who specialize in growth securities tend to use short-term return signals while value investors tend to use longer-term signals. Different investors exhibit differences not only in how they respond to a return signal (momentum or contrarian), but they are also different in the type of signal to which they respond. While it is important to understand what signal horizons are relevant for trading decisions, the prior literature has not explicitly studied different investment horizons. Typically, a horizon of one day, a month, or three months is chosen and remains fixed throughout the analysis. Our results suggest the importance of a flexible approach, where the analysis allows for interaction between signal horizon and the type of asset being traded. ${ }^{8}$

\footnotetext{
${ }^{8}$ Results are provided in appendix A.
} 
We use value and growth styles in this study because the popular press and recent academic literature make a clear distinction between value and growth investments. The two styles naturally lead to different investment contexts (Benz 2005, p. 93). Regarding value investing, "value investors often look for quiet, out-of-favor, 'boring’ companies that have excellent financial performance. Investing in such stocks assumes that the stock price will eventually rise to match the intrinsic value.” (Warren 2009, p. 652). The concept behind value investing challenges the efficient markets hypothesis in that the investors look for undervalued assets in order to gain a long-term (eventual) return. Value investors buy when prices are low. This idea is echoed by Klarman (1991), "Value investing by its very nature is contrarian.” (p. 165). ${ }^{9}$

Growth securities and investors are painted differently. Whereas value investors look for cheap securities, the growth investor wants to buy the "Ferraris of the stock market" hoping to "ride the wave" to higher returns (Warren 2009, p. 652). Growth investors are willing to buy at any price with the belief that earnings growth will lead to significant price appreciation. Contrary to the efficient markets hypothesis, growth investors believe that growth opportunities are not correctly incorporated into prices, leading to the search for stocks that will provide quick momentum-related returns.

This is not the first paper to study trading patterns of investors. Stock trading by individual investors has been studied by several authors: Odean (1998, 1999), Barber and Odean (2000, 2001, 2002), Grinblatt and Keloharju (2001), Lee and Kumar (2006), and Kaniel et al. (2008). It has been documented that investors use past returns to make trading decisions. Using daily mutual fund trades, Goetzmann and Massa (2002) find that some investors in an S\&P 500 index fund follow a momentum strategy while others follow a contrarian trading strategy. Odean (1998) and Grinblatt and Keloharju (2001) find evidence of the disposition effect ${ }^{10}$ —investors hold on to their poor performing stocks but sell stocks exhibiting past high returns. Kaniel et al. (2008) report that past returns influence investors’ buying and

\footnotetext{
${ }^{9}$ Christine Benz has worked as an analyst and editor for Morningstar since 1993. Carl Warren is a professor emeritus at the University of Georgia. Seth Klarman is a hedge fund manager for Baupost Group. His out-of-print book currently sells for over $\$ 2000$ on Amazon.com.

${ }^{10}$ See Shefrin and Statman (1985).
} 
selling decisions for stocks. Lee and Kumar (2006) argue that the trading behavior of retail investors focused in particular segments or styles contribute to observed pricing anomalies. The unique feature of our study is the comparative analysis of how individual investors trade across styles and how trading decisions are affected by the types of securities being traded.

The paper proceeds as follows. Section 2 describes our data. The description of the methodology and results reporting the trading behavior of style investors are provided in section 3 . The analysis of multi-style trading behavior is listed in section 4. Concluding remarks follow in section 5 . Results on the different signal lengths and several tests for robustness have been placed in an appendix at the end of this paper.

\section{Data}

This study employs a unique data set containing anonymous individual account activity provided by a large mutual fund complex. ${ }^{11}$ The daily data include all trades made by clients, identified by a unique account number, for two mutual fund styles within the complex from 1997-1999. ${ }^{12}$ The data consists of daily activity records for all accounts that existed or were formed in the three-year sample period. All individual identifying characteristics of these accounts were removed by the data provider. From the different mutual funds available to us, we identify six mutual funds that describe themselves as being growth oriented and five funds that describe themselves as being value oriented. ${ }^{13}$

\footnotetext{
${ }^{11}$ No identifying characteristics of the account were given to researchers, keeping accounts anonymous.

${ }^{12}$ Most of the mutual funds sell various classes of shares (i.e. Class A, Class B, etc.). We include all share classes in the study.

${ }^{13}$ It is important to point out that our study is based on data on trading mutual funds and not individual stocks. This provides several important advantages. First, we (as researchers) do not need to categorize assets into value and growth categories, and therefore do not suffer from our criteria being ad hoc or different from the criteria employed by the market participants. Value and growth mutual funds are categorized, named, and marketed as such by the mutual fund family that provided the data. Second, investors in our data set who trade both value and growth funds trade exactly the same assets as value-only and growth-only investors. For example, their information sets contain the same past performance information.
} 
The data identifies the account as being held by an individual, a broker, a trust, a corporation, or retirement account (both 401k and IRA). Since we are interested in the timing decisions of investors, we remove all trades associated with retirement investing. Retirement funds are often invested according to a predetermined schedule (bi-weekly or monthly) and therefore do not reflect the timing decisions of the investor. All other investor types are included.

Table 1 provides statistics for our sample. We categorize the data into four groups: the value trades made by value investors, the growth trades of growth investors, the value trades of multi-style investors (who hold both value and growth funds), and the growth trades of multi-style investors. We identify 87,458 different accounts that fit the description of one of the three investor types. This is comparable to the number of accounts used in other studies. ${ }^{14}$

We first notice the popularity of growth investing during our sample period. There are more growth investors than both value investors and multi-style investors. Growth investors trade more often in our sample, trading an average of 4.4 times. Value investors, on the other hand, trade on average only 3.07. Investors trading both growth and value also exhibit interesting trading behavior. These investors trade growth over three times as much as they trade value (9.83 growth trades per investor versus 3.11 value trades per investor). However, trading is highly skewed with many account holders trading only once during our sample period. This is not unusual. Individual mutual fund investors studied by Ivkovic and Weisbenner (2009) make average (median) purchases of 8.5 (3.0) in their taxable accounts over the six-year period 1991-1996.

The time between trades is homogeneous across value investors, growth investors and multi-style investors. The median frequency in trading is the same across the three investor types-roughly 30 days between trades. It is common to have trades automated to occur at a pre-set frequency time (monthly, bi-

\footnotetext{
${ }^{14}$ For comparison, Barber and Odean (2000) study 66,465 investors, Graham and Kumar (2006) use 60,000, Ivkovic and Weisbenner (2009) use 32,259 mutual fund investors, Odean $(1998,1999)$ chooses 10,000 individual accounts, and Barber and Odean (2002) analyze 1607 investors who switched from phone-based to online trading during the 1990s.
} 
weekly, etc). This type of trading adds noise to our analysis since such type of trading is not based on market timing. Interestingly, though, we find many occurrences of multi-style investors trading both value and growth on the same day; we find a median time of 5.6 (average of 32 days) days between consecutive value and growth trades by the same individual.

Overall, the evidence suggests differences in the way growth funds and value funds are traded. Growth funds, whether traded by growth investors or multi-style investors, are more frequently traded than value funds. We investigate the differences in trading behavior more rigorously in the next sections.

3. Growth traders versus value traders

3.1. Identification of momentum and contrarian investors

We use individual account activity to classify investors according to their pattern of share purchases and redemptions. For each growth investor and value investor, we classify each trade as being a momentum purchase, contrarian purchase, momentum sell or contrarian sell. This classification is conditional on a predetermined past return signal. All purchases that occur on the day after observing a positive (negative) return signal are considered momentum buys (contrarian buys). Likewise, all redemptions that occur on the day after observing a negative (positive) return signal are considered momentum sells (contrarian sells). Positive feedback traders (momentum investors) react by purchasing when prices rise and selling when prices fall. Negative feedback traders (contrarian investors) are characterized in exactly the opposite fashion, buying after a drop in price and sell after a rise.

An individual investor is then classified as a momentum buyer, contrarian buyer, momentum seller, contrarian seller, or undetermined depending on the number of trades the individual agent made that were consistent with the strategy. We classify the investor as a momentum buyer if the number of purchases occurring on days following a positive return signal is significantly greater than that expected assuming a random distribution of trades. The same method is used to determine contrarian buyers, 
momentum sellers and contrarian sellers. Those that do not fit into one of the trading strategies are classified as undefined. Following Goetzmann and Massa (2002), we use a binomial distribution to determine whether the number of trades following a particular strategy is greater than expected if the investor traded randomly. This statistic is equivalent to a 'backwards-looking' Henriksson and Merton (1981) timing test, and thus its properties are well-understood. The probability is determined using

$$
P(X>x)=1-\sum_{y=0}^{x-1}\left(\begin{array}{l}
n \\
y
\end{array}\right) p^{y}(1-p)^{n-y},
$$

where $\mathrm{n}$ is the total number of buys (or sells), $\mathrm{x}$ is the number of buys (sells) consistent with a particular strategy, and p is the probability of observing a particular return signal. To determine the probability p, we use returns over the five-year period prior to our sample period plus the three years of our sample period - the eight-year period 1992-1999. The probability of a positive return signal is equal to the ratio of observed positive returns over total number of days. The investor classification methodology takes into account market conditions because it includes the probability of observing a particular return signal, p. ${ }^{15}$ We discuss the robustness of our results to this choice in appendix B. ${ }^{16}$

To classify an investor, the individual must not only trade consistently, but, more fundamentally, he must trade. As seen in table 1, the median number of trades is one for both growth investors and value investors. Such investors are unclassifiable. To eliminate some noise in our analysis we consider only those investors who trade (either buy or sell) at least four times in our sample. ${ }^{17}$ We are left with 834 value investors and 12,884 growth investors. Table 1, panel B lists summary statistics for this subset of

\footnotetext{
${ }^{15}$ For example, let the probability of observing a positive return signal be $\mathrm{p}=0.5$. Then, an investor who is trading at random, without following a particular trading strategy, will make half of his purchases on a day following a positive return signal, and half of the purchases will fall on a day following a negative return signal. In a different market condition, for example when the probability of a positive return signal is higher, $p=0.60$, an investor who is trading at random will make approximately $60 \%$ of his purchases on a day following a positive return signal.

${ }^{16}$. We follow the prior empirical literature on investor trading behavior and investigate simple historical returns. Since theory does not provide sufficient basis for the selection of the signal horizon, and because a priori different past return horizons may be relevant for investor trading decisions, we investigate several different prior return signals. The evidence must be interpreted in this light

${ }^{17}$ In the attached appendix, we show that our results are robust to the choice of the filter.
} 
the data. There are many instances of individual agents making multiple growth or value trades within the same day, thus multiplying the reaction to a single signal. This can have the effect of falsely associating the agent with a particular trading strategy. To eliminate this possibility, we aggregate all trades (both buys and sells) made by the same investor within the same style on the same day to a single trade. We classify investors using seven different past return signals. This is one of the important contributions of this paper. While past studies focus on the previous day’s return as the signal to classify momentum and contrarian trading behavior, it is important to investigate other return histories. It is a priori unclear how far back investors look to determine their trading strategies. Many trading strategies (moving average strategies, for example) use days or months of past return data as a signal to trade. Further, past research has shown that returns exhibit positive serial correlation over short horizons and negative serial correlation over longer horizons (Jegadeesh and Titman 1993). We, therefore, calculate past return signals using (Pt-1 - Pt-1-j)/ Pt-1-j for j = 1, 5, 10, 20, 40, 60, and 90 days. We choose the intervals to correspond to one day, a calendar week (five trading days), a calendar month (20 trading days), and a quarter, among others. We use the notation j-day to distinguish the various past return windows. Using these return signals, which range from the previous day’s return to the previous 90 trading days' return, we let the data tell us which signals are important. ${ }^{18}$

\subsection{Classification results}

The results of the classification are provided in tables 2 and 3. Table 2, panels A and B show the classification of value buyers and growth buyers. We use five categories: strong momentum, weak momentum, undefined, weak contrarian and strong contrarian. Strong and weak investors are defined by statistical significance where strong momentum and strong contrarian investors have p-values less than $10 \%$ (indicating $10 \%$ or smaller probability of observing the pattern of trades by chance), and weak

\footnotetext{
18 Studying trades in and out of mutual funds is particularly interesting because there is no immediate opposing trade. When an investor buys a stock, another must sell. If we use the previous day's return as a trading signal, then every momentum trade must be matched with a contrarian trade. Mutual funds are different. An investor may move in and out of the mutual fund without the need of an immediate opposing trade.
} 
momentum and weak contrarian investors have p-values between $10 \%$ and $50 \%$. An investor is considered undefined if the p-value is greater than $50 \%$ for both the momentum and contrarian strategies. Such investors either did not trade in a consistent way or did not trade a sufficient number of times.

We first observe that both momentum and contrarian investing strategies are used by groups of value and growth investors. For the 1-day return signal, 1.94\% of value investors and 5.35\% of growth investors are classified as strong momentum buyers while $5.67 \%$ of value investors and $4.59 \%$ of growth investors are classified as strong contrarian buyers. For this signal, we are unable to classify $52 \%$ of the value investors and $58.5 \%$ of the growth investors. ${ }^{19}$

Over all return signals, value investors tend to be more contrarian in their purchases while growth investors tend to be more momentum oriented in their purchases. This can be seen in panel C of table 2 where we report the results of the Mantel-Haenzel test. We compute the average investor type for both growth and value investors. All contrarian investors (both strong and weak) receive a score of -1 , momentum investors (both strong and weak) a score of +1 , and unclassified investors a score of 0 . The average of the scores over all investors in each style is a number between -1 and +1 . Positive values indicate that, on average, the investors follow a momentum buying strategy, while negative values indicate that, on average, the investors follow a contrarian buying strategy. Using the Mantel-Haenszel chi-square statistic, we test whether the average growth investor type is the same as the average value investor type. Results indicate a clear difference in trading strategy that is dependent on the style of the security being purchased. These results are robust to the choice of the scoring system.

The average growth investor follows a momentum strategy for all return signals, although at shorter horizons (up to 10 trading days) contrarian behavior has a strong presence among growth investors. Figure 1 plots the average investing style of the growth investor at each signal horizon. Positive values indicate momentum tendencies, on average, while negative values indicate average

19 These results are comparable to the findings of Goetzmann and Massa (2002), who study investors in an S\&P 500 index fund. They find that $1.08 \%$ of all buyers are strong momentum traders, $2.36 \%$ are strong contrarian investors, and $68 \%$ are unclassified. The method performs well in our setting. For all return signals we are able to classify at least as well. 
contrarian tendencies. As the trading signal increases in length, more investors are classified as following a momentum strategy. For the 1-day signal, 5.35\% are considered strong momentum but at the 90-day signal, $16.01 \%$ can be classified as being strong momentum investors. On average, growth investors exhibit momentum buying behavior. At the 1-day signal, 5.35\% are classified as strong momentum while $4.59 \%$ are strong contrarian.

Value investors are different. As figure 1 and table 2 both show, value buyers are contrarian investors for all return signals. Whereas the average investing strategy is near zero for some signals with the growth investors, the average value investor is clearly contrarian. Momentum investing is present, but is less than $2 \%$ for five of the seven signals. The proportion of value investors classified as contrarians increases with the longer horizon signals. Later we also test whether the strategies followed by value investors rely on longer-term signals rather than very short signals.

The differences between value and growth investors are also evident from figure 3 . The figure shows the distribution of trading strategies for the seven return signals. Two patterns emerge from the figure when the distribution for value investors (top left graph) is compared with the distribution for growth investors (top right). First, compared with growth investors, value investors exhibit a stronger tendency for contrarian purchases at any past signal horizon. For a given return signal, there are more contrarian buyers among value investors, and there are more momentum buyers among growth investors. Second, the figures illustrate the importance of the signal horizon. The distribution of contrarian and momentum traders changes with the signal horizon. Some investors are unable to be classified using some signals but can be classified using other signals.

Not only are growth and value traders different in their buying behavior, they are also different in their selling behavior. Table 3 shows the classification of value and growth sell strategies. There are growth and value sellers who follow a contrarian strategy (sell when past returns are positive) and there are investors who follow a momentum strategy (sell when past returns are negative). Using the 1- day return signal, $7.69 \%$ of value investors and $1.82 \%$ of growth investors are classified as strong momentum 
sellers and $2.56 \%$ of value traders and $3.25 \%$ of growth investors are classified as strong contrarian sellers. We are unable to classify $51 \%$ of the value investors and $56 \%$ of the growth investors. ${ }^{20}$

Table 3 (panel C) and figure 2 provide the average growth and value investor types. Similar to the buy scoring system, all momentum sellers are given a score of +1 , all undefined investors receive a score of 0 , and all contrarian sellers are given a score of -1 . A positive value implies that, on average, the investors are momentum traders, while a negative average implies that, on average, investors are contrarian. The average growth seller is positive but near zero, with approximately equal numbers of contrarian and momentum traders, for the 1-day, 5-day, and 10-day signals. The average, however, becomes negative for the longer horizon signals, indicating that growth investors are contrarian sellers. The highest average (in absolute value) is found using the 90 -day return signal. More than $8 \%$ of growth sellers are classified as strong contrarian using this signal compared with only $0.42 \%$ classified as strong momentum. Growth investors tend to sell when markets rise. This is consistent with the disposition effect that describes the investor behavior of holding losers and selling winners. ${ }^{21}$ This is true for all of the longer return signals.

Again, we find that value investors behave differently. Value investors are momentum sellers for all signals. The Mantel-Haenszel chi-square statistics show that the average growth investor and the average value investor are significantly different for all signal horizons. More so than growth sellers, value investors sell when they observe falling returns.

Figure 4 illustrates the difference between the value investors (upper left graph) and growth investors (upper right). The figure shows the distribution of different investor types for various past return signals. The figure also shows the importance of the length of the return signal. ${ }^{22}$

\footnotetext{
${ }^{20}$ Goetzmann and Massa (2002) find $0.11 \%$ of investors are momentum sellers, $0.27 \%$ are contrarian sellers, and $87 \%$ are unclassified for investors in the S\&P 500 index fund.

21 See Odean (1998), Locke and Mann (2005), Frazzini (2006), Statman et al. (2006), and Goetzmann and Massa (2008) and references therein for discussions regarding the disposition effect.

22 In appendix A we perform a detailed analysis of classification with respect to different past return signals and find significant differences between growth and value investors with respect to the signal horizon used: growth investors tend to rely on short-term signals, while value investors tend to respond to long-term signals. This important issue has not been explored in the literature. Each investor in our sample is classified by the signal most
} 
The tests above are based on classifying individuals according to their trading strategy. Our results indicate important differences between value and growth investors. We find the existence of both momentum and contrarian investing by both growth and value investors. Growth investors tend to follow a momentum buy and contrarian sell strategy. Value investors tend to follow a contrarian buy and momentum sell strategy.

4. Multi-style investors-Consistency in trading strategies

An important question remains. To what extent does the propensity to trade in a certain way reside with the investor, such as age, gender and risk aversion, and to what extent does it depend on situational factors, such as the type of asset being traded? In this section we study the trading behavior of investors who trade in both growth and value styles (multi-style investors). By comparing multi-style investors with value-only and growth-only groups we are able to differentiate between the personality theory and the situation-dependent theory.

The propensity to trade in a certain fashion—momentum or contrarian—may be a characteristic of an individual investor. In much the same way it is assumed that an individual has a particular aversion to risk, an investor may be naturally prone to trade different assets according to a consistent trading rule. For example, an investor may show contrarian or momentum investment characteristic when investing across different assets. This is a feature of the prior literature on trading behavior where an important latent assumption is maintained that it is highly unlikely for an investor to display different trading

likely to be used to make investment decisions (the signal that gives the lowest probability of observing a given trading pattern by chance). Consistent with the main results, momentum buying dominates contrarian buying for growth investors (55.15\% of growth investors follow a momentum strategy), while for value investors the contrarian buying strategy dominates the momentum strategy (64.26\% of value investors are classified as contrarian). Growth investors tend to respond to short-term information, in contrast to value investors who rely on longer-term signals. With respect to redemptions, growth investors tend to be contrarian, while value investors are momentum (this is consistent with the main results). Value investors rely on longer-term signals than growth investors in their selling behavior, just as they do in their purchases. We find that different investors exhibit differences not only in how they respond to a return signal (momentum or contrarian), but they are also different in the type of signal to which they respond. 
strategies across different types of investments. In such a setting, it is not likely for an individual to be a momentum investor for certain assets and a contrarian investor with respect to a different set of assets.

A number of behavioral models are based on the idea that investors are prone to behavioral heuristics and have inherent biases in the way they interpret and use information. ${ }^{23}$ For example, investors may apply a 'representative heuristic' which may lead them to mistakenly conclude that firms realizing extraordinary earnings growth will continue to experience similar extraordinary growth in the future (Barberis et al. 1998). ${ }^{24}$ Shefrin and Statman (2000) develop a behavioral portfolio theory describing the portfolios held by individuals who categorize assets in mental accounts and then ignore the covariance between them. Each mental account is designed to meet particular aspiration levels such as high versus low risk, or fast versus slow growth. In our setting, the personality factor implies than an individual who trades both value and growth will exhibit the same propensity to trade in both value and growth holdings. A momentum investor will be expected to display momentum trading in both value and growth trades. A contrarian investor will use contrarian strategies in both styles.

There is an important alternative, however. In addition to an invariant, inherent personality-trait component, risk taking may be related to situational factors. Tversky and Kahneman $(1974,1981)$ and Thaler (1985) show that different situations, referred to as 'situational frames', can cause preferences to depend on the formulation of decision problems. It has been argued that asset characteristics contribute to how investors make decisions. For example, investors frequently classify assets into categories (or styles) and then express their demand for risky assets at the levels of these categories (Barberis and Shleifer 2003). The approach that investors take to form expectations about the performance of different categories (styles) may depend on a chosen style. Characteristic of the asset—or perceived characteristics—can potentially alter the way in which investors think about that asset. When asset

${ }^{23}$ Tversky and Kahneman (1974), Barberis et al. (1998), Daniel et al. (1998), and Hong and Stein (1999).

${ }^{24}$ Representative heuristic is the tendency of individuals to identify an uncertain event, or a sample, by the degree to which it is similar to the parent population (Tversky and Kahneman 1974). 
characteristics themselves play a role in how investors trade, the same investor can exhibit different trading patterns depending on the characteristics of the assets.

Very little is known whether a given investor would tend to form expectations about different categories of assets in a consistent, similar fashion, or whether an investor would apply different models for forming expectations depending on the classification or characteristics of the assets. Understanding context-dependent investment decision making is important.

A decision-making mechanism based on priming of identity relies on the potential for one or the other investment styles to be made salient in an investor who holds both types of funds. A single investor can maintain a latent identification with multiple groups, or styles, and priming can make one of the multiple identities prominent for decision-making. An investor holding shares in both growth and value funds may identify with the philosophy and subscribe to the implied trading behavior of both investment styles at once, even though, in certain contexts, this may imply opposite responses to past price signals. Using the sample of individual investors who trade both growth and value, we test whether investors use the same trading strategy across styles or whether they apply different strategies to different styles.

\subsection{Classification analysis}

We classify all multi-style investors as momentum, undefined, or contrarian according to their value trades and then classify all investors according to their growth trades. Each investor falls into one of nine categories based on their value classification and their growth classification (momentum, unclassified or contrarian for value trades times the same three categories for their growth trades).

Figures 3 and 4 illustrate the distribution of multi-style investor types for buys and sells, respectively. ${ }^{25}$ These figures allow us to clearly compare the distribution of trading behavior of the multistyle investors' value trades (lower left) with the distribution of behavior of the value-only investors'

\footnotetext{
${ }^{25}$ For figures 3 and 4, we plot only those investors who trade at least four times total (sum of value and growth trades). This allows for a more direct comparison with the plots for value and growth style investors also provided in figures 3 and 4.
} 
trades (upper left), and compare the multi-style investors' trades of growth funds (lower right) with the distribution of behavior of growth-only investors (upper right).

The figures illustrate two important findings. First, multi-style investors trade differently across their value and growth holdings. Second, the figures show striking similarities between the way multistyle investors trade their value holdings and the way value-only investors trade, and between the way multi-style investors trade their growth holdings and the way growth-only investors trade. Multi-style investors trade their growth holdings in a similar way as the growth-only investors, but trade like the value-only investors in their value trades. This is true for both purchases and redemptions.

We proceed with a more formal analysis of these tendencies. For each investor we match his value trading strategy with his growth trading strategy. A majority of investors are classified as undetermined in one or both investment styles. Nonetheless, we find the existence of investors who trade consistently following a single strategy for both value and growth (both momentum and contrarian) and we find some investors who trade inconsistently following one strategy in one style but a different strategy in the opposing style. This is evidence supporting both the personality theory and the situationdependent theory. We adopt the convenient notation 'Strategy G/Strategy V' where Strategy G refers to the strategy used when trading growth and Strategy V refers to the strategy used when trading value.

Results are listed in table 4. Panel A describes the classification of purchases and panel B describes the classification of redemptions. With respect to purchases (panel A), we can judge the consistency of investors trading by comparing investors labeled as Momentum/Momentum or Contrarian/Contrarian with the investors who are labeled as Contrarian/Momentum and Momentum/Contrarian. By observation, we notice that consistency is challenged by the existence of Contrarian/Momentum and Momentum/Contrarian investors. For all return signals, more investors are classified as Contrarian/Contrarian and Momentum/Contrarian (suggesting a contrarian strategy for value fund trades) than are classified as Contrarian/Momentum or Momentum/ Momentum. Specifically, more investors are classified as Contrarian/Contrarian for the shorter-term signals while slightly more investors are classified as Momentum/Contrarian for the longer-term signals. Less than 5\% of the investors (across 
all signals) can be classified as Momentum/ Momentum and an even smaller percentage of investors (1\% or less) follow the Contrarian/Momentum strategy. This result shows the strong connection between the value investing and the contrarian trading strategy.

The overall pattern is surprising. The table shows that a large fraction of investors trade differently across asset classes-momentum in growth but contrarian in value. These investors trade like the growth-only investors in their growth trades but trade like the value-only investors with their value trades. This supports the situation-dependent theory and is consistent with the contextual hypothesis.

Consistency in trading implies that an individual who trades growth according to a momentum strategy must also trade value using the same strategy. At the same time, investors who follow a contrarian strategy for the value assets must also follow the same strategy with their growth assets. The McNemar's test indicates that there are significantly more growth trades of multi-style investors classified as momentum than there are value trades classified as momentum, and there are significantly more value trades classified as contrarian than there are growth trades classified as contrarian. ${ }^{26}$ The test is applied to a 2 X 2 contingency table, where the columns are Growth Momentum and Growth Contrarian, and the rows are Value Momentum and Value Contrarian. The cells contain the number of investors in each category. Statistical significance means that the inconsistent (off-diagonal) investors are not equal, indicating the unequal use of a strategy with a particular style. As seen in table 4, panel A, the equality (consistency) is rejected for all cases. There are significantly more contrarian value buyers than contrarian growth buyers, and there are significantly more momentum growth buyers than momentum value buyers. Multi-style investors who trade differently in their growth and value funds tend to be contrarian value and

\footnotetext{
${ }^{26}$ McNemar's test determines whether we classify the same number of momentum growth investors as we find momentum value investors and if we classify the same number of contrarian growth investors as we classify contrarian value investors, indicating consistency. Hence, the test compares Mom|Mom+Mom|Contra=Mom|Mom+Contra|Mom, Contra|Contra+Contra|Mom=Contra|Contra+Mom|Contra. The test above is the same as comparing the size of the off-diagonal cells (due to canceling like terms). McNemar statistic is computed as: $Q=(\mathrm{Mom} \mid \text { Contra-Contra|Mom })^{2} /(\mathrm{Mom} \mid$ Contra+Contra|Mom), where $Q$ follows a chisquared distribution. Statistical rejection implies that there is a significantly larger group of buyers who are Mom|Contr compared with Contr|Mom, and there is a significantly larger group of sellers who are Contr|Mom compared with Mom|Contr.
} 
momentum growth buyers. These are the same tendencies as for growth-only and value-only investors. This statistical test confirms the patterns reported in figure 3.

The findings for selling behavior (table 4, panel B) are the same. Symmetry is strongly rejected in all but two cases. There are significantly more momentum value trades than momentum growth trades, and there are significantly more contrarian growth trades than contrarian value trades. This result again reinforces the finding that investors who trade growth tend to follow a momentum buying and contrarian selling strategy while investors who trade value tend to follow a contrarian buying and momentum selling strategy. Here, too, multi-style investors who trade differently in their growth and value funds tend to behave similarly to growth-only investors in their growth trades, and similarly to value-only investors in their value trades. This statistical test confirms the patterns reported in figure 4.

Supplemental evidence comes from two additional tests of trading consistency-the kappa coefficient and the log odds ratio test. The kappa coefficient is a statistical measure of consistency (or agreement) and describes the difference in the amount of agreement beyond that expected by chance. ${ }^{27} \ddagger$ If there is complete agreement (all investors are Momentum/Momentum or Contrarian/Contrarian), then kappa will equal one. Values of zero or less than zero indicate no agreement. As a rule of thumb, values of kappa above 0.4 are generally considered moderate agreement and values above 0.8 as excellent (almost perfect) agreement. ${ }^{28}$ The provided test determines if kappa is equal to zero-no consistency in trading strategies across asset classes.

The log odds ratio test compares the number of individuals who trade consistently to those who trade inconsistently. ${ }^{29}$ The value ranges from minus infinity to positive infinity with negative values

\footnotetext{
${ }^{27}$ Kappa is defined as $\kappa=\left(\Pi o-\Pi_{e}\right) /\left(1-\Pi_{e}\right)$, where $\pi_{o}=\sum \pi_{i i}$ is the observed agreement and $\Pi_{e}=$ $\sum \pi_{i+} \pi_{+i}$ is the expected agreement. The value $\pi_{i j}$ is the probability of an individual being classified in the $i$, $j$ th category.

${ }^{28}$ Cohen (1960) and Fleiss (1981).

${ }^{29}$ The $\log$ odds ratio is defined as $\log (O R)=\log \left(\frac{n_{m / m} n_{c / c}}{n_{m / c} n_{c / m}}\right)$, where $n_{i / j}$ is the number of individuals classified as $i / j$. The log ratio is normally distributed with mean of zero and variance

Of $\operatorname{var}(O R)=\frac{1}{n_{m / m}}+\frac{1}{n_{m / c}}+\frac{1}{n_{c / m}}+\frac{1}{n_{c / c}}$.
} 
indicating no agreement and positive infinity indicating complete agreement. As with the kappa coefficient, we test if the log odds ratio is equal to zero indicating no consistency in trading strategies across asset classes.

For buying behavior, we can conclude that there is little agreement between the strategies each individual uses with their growth trades and the strategies the same investor uses with their value trades. Using both statistics we reject the hypothesis that there is no agreement in trading strategies across asset classes for several cases. The hypothesis of no agreement is not rejected for the longer-term signals primarily using the log odds ratio (supporting the main results of no agreement found with the McNemar test). Statistically speaking, there may exist some consistency in trading with the short-term signals but there is no consistency with the long-term signals. Even in cases of some statistical consistency in trading strategies across asset classes, the values of the statistics are rather small. Both kappa and the log odds ratio are small, supporting the existence of a large proportion of investors who react to past returns differently in their buys into value than their buys into growth.

Similar differences in behavior can be seen in the selling patterns (table 4, panel B). The log odds ratio and the kappa coefficient provide slightly different results. We reject the hypothesis of no agreement in nearly all cases using kappa, but fail to reject using the log odds ratio. However, we mostly observe kappas below 0.2, suggesting that although statistically significant, the level of agreement is small. Overall, we find a strong presence of investors using different strategies for the different styles.

A significant number of investors do not follow the same trading rules between asset classes. For multi-style investors who fall in this category, we find that they tend to trade their growth funds similarly to growth-only investors, and they tend to trade their value funds in a fashion similar to value-only investors. These findings are consistent with the contextual hypothesis.

\section{Conclusion}


Investors use patterns in prices to determine when to buy and sell financial securities. It has been previously shown that some investors follow a contrarian strategy while other investors follow a momentum strategy. However, it is important to understand to what extent trading styles are inherent vs. contextual.

In this paper we study the investing strategies of three distinct groups of investors: those who specialize in growth securities, those who specialize in value securities, and those who trade both growth and value securities. We find significant differences in how these three groups trade. Value investors tend to buy after prices fall, and sell as prices decline. Growth investors tend to buy after price increases and sell after observing positive returns. Thus, value investors tend to be contrarian buyers, while growth investors tend to be momentum buyers. Further, we show that growth investors tend to rely on short-term signals while value investors follow longer-term signals. Value and growth investors exhibit significant differences in how they approach the buying and selling of securities. They exhibit differences not only in how they respond to a return signal (momentum or contrarian), but also in the type of signal to which they respond.

After establishing trading patterns of growth investors and value investors, we study investors who trade in both value and growth. To investigate inherent vs. contextual behavior, we propose a mechanism based on priming of identity. The proposed mechanism relies on the potential for one or the other investment style to be made salient in an investor who holds both types of funds. A single investor can maintain a latent identification with multiple styles, and priming can make one of multiple identities prominent for decision-making. Our findings are consistent with the hypothesis that the trading style of an individual is not independent of context, but instead may be influenced by the characteristics of the investment. The multi-style investors in our sample exhibit different trading behavior depending on the style of the traded security. The multi-style investors trade growth like the growth-only investors, and they trade value like the value-only investors.

This paper adds to the literature describing how investors trade. In the prior literature on investor trading behavior, it has been subtly assumed that investors are initially endowed with a particular trading 
behavior and therefore the consistent behavior can be modeled relatively easily using a utility function. Our results indicate that the choice of trading strategy may depend in a significant way on the characteristics of the security being traded. The same individual chooses a momentum strategy when trading growth assets but chooses a contrarian strategy when trading value assets.

Collectively, our results call attention to the importance of asset characteristics and investment environment as determinants of trading behavior. Current theories do not explain our results. For example, portfolio rebalancing does not explain why the same multi-style investor trades in ways similar to both the value-style investor and the growth-style investor-contrarian in value and momentum in growth. Such a theory would need to explain (1) the simultaneous existence of growth investors, value investors, and multi-style investors and (2) why value assets are associated with a contrarian strategy using longer-term signals while growth securities are associated with a momentum strategy relying on shorter-term signals. The mechanism of priming of identity, however, has a potential to explain this. Investors have identified the popular asset styles of value and growth as being different and thus worthy of differential treatment. 


\section{Acknowledgement}

We thank Peter Bossaerts, Glenn Boyle, Marie-Hélène Broihanne, Elroy Dimson, Daniel Dorn, Bart Frijns, Bruce Haslem, Ravi Jagannathan, Andrei Jirnyi, Michael Keefe, Joni Kokkonen (discussant), Deborah Lucas, Maxime Merli, Elvira Sojli, Alireza Tourani-Rad, Patrick Roger, Tristan Roger (discussant), Sergei Sarkissian, Clemens Sialm, Remco Zwinkels (discussant) and the participants at the Rotterdam Conference on Professional Asset Management, the SunTrust FSU Finance Spring Beach Conference, 2011 Auckland Finance Meeting, 2012 EFM Symposium Asset Management in Hamburg, $29^{\text {th }}$ International Conference of the French Finance Association in Strasbourg, 2012 FMA European Conference in Istanbul, Turkey, European Financial Management Association 2012 Annual Conference in Barcelona, Spain, 2012 1 st Luxembourg Asset Management Summit, 2013 IFC7 Conference in Paris, France, seminar participants at Cornell University, Hersh Shefrin (Editor) and two anonymous referees for helpful suggestions. All remaining errors are ours. A portion of this research was undertaken when Andrey Ukhov was visiting Northwestern University, whose support is greatly appreciated. 


\section{Appendix A. Classification of investors by return signal}

In the main analysis of value-only and growth-only investors we discuss several possible signal horizons and study the differences between value and growth traders for each horizon. We find that some agents can be classified using short-term signals while other agents can only be classified using the longterm signals, indicating that agents have different horizons. We now advance the analysis by classifying each investor by the signal most likely being used to make investment decisions. This is an important issue not yet explored in the literature. Different investors exhibit differences not only in how they respond to a return signal (momentum or contrarian), but they are also different in the type of signal to which they respond. In this appendix we double sort all agents first by trading strategy and then by trading signal. This is the first study to classify individual investors according to signal horizon.

To investigate the potential differences between value and growth investors with respect to signal length, we proceed as follows. For each investor in the dataset we determine the signal length (1-day, 5day, etc.) that results in the lowest p-value in the binomial classification method—an approach similar to choosing the model providing the best fit. The investors are still classified as momentum or contrarian (or unclassified), but now for each investor we determine the signal length with the greatest statistical support.

Table A1 reports the results for investor buying behavior. This table lists the percent of all value investors (panel A) and all growth investors (panel B) according to the trading strategy and trading signal that most precisely classifies their trading behavior. Whereas in tables 2 and 3, each investor is evaluated using each trading signal so that the column sum always equals $100 \%$, in table A1, each investor appears only once, at the signal that gives most precise classification for the trading strategy.

Consistent with the main results, momentum buying dominates contrarian buying for growth investors while for value investors the contrarian buying strategy dominates the momentum strategy. In the aggregate, $55.15 \%$ of growth investors follow the momentum strategy (23.54\% are classified as strong momentum). Though fewer than the momentum investors, we do find a number of contrarian investors: $35.33 \%$ of growth investors are contrarian investors (12.43\% are strong contrarian). Value investors 
exhibit a strong tendency toward contrarian buying: $64.26 \%$ of value investors are classified as contrarian in their purchases (44.84\% as strong contrarian). Only $14.27 \%$ of value investors are momentum investors in their purchases (5.04\% are strong momentum). Sorting investors by strategy and signal allows us to classify $78.54 \%$ of the value investors and over $90 \%$ of the growth investors.

There are interesting differences in signal horizon between growth and value investors. Comparing the percent of growth and value investors at each signal, we find that the greatest percentage of growth investors use the 1-day signal while the greatest percentage of value investors use the 90-day signal. We classify $19.27 \%$ of all growth investors using the 1-day return signal and $33.33 \%$ of value investors using the 90-day signal.

Another way to compare signal horizons across the two groups of style investors is to compare short-term signals with long-term signals. Let the short-term signals be the 1-day through 10-day signals and the long-term signal as the 40-day through 90-day signals. We find that $44.97 \%$ of all growth investors and $27.09 \%$ of all value investors rely on short-term signals. On the other hand, 34.94\% of growth investors and $45.32 \%$ of value investors follow the long-term signal. Growth investors tend to respond to short-term information as compared with value investors who rely on longer-term signals.

Consider the selling behavior as described in table A2. Overall, we are able to categorize fewer investors according to their redemptions as compared with their purchases. Investors in our sample bought more than sold. For growth investors, contrarian selling is more strongly present than momentum selling. In the aggregate, $8.11 \%$ of growth investors are strong contrarian and 3.99\% are strong momentum sellers (although the percentages are nearly equal when the weak classification is included). Value investors exhibit tendencies toward momentum selling: $27.22 \%$ of value investors are classified as strong momentum in their sales while only $3 \%$ of value investors are strong contrarian sellers. This is consistent with the main results.

Similarly to the differences in buying behavior, growth and value investors also use different signal horizons to determine when to sell. Over all trading signals, the largest percentage of growth investors $(11.59 \%)$ is best described as using the 1-day trading signal. In contrast, the largest percentage 
of value investors (27.82\%) appears to use the 90-day signal. This suggests that value investors rely on longer-term signals than growth investors in their selling behavior, just as they do in their purchases.

The tendency for growth investors to rely on shorter-term signals and value investors to rely on long-term signals is even more evident when aggregating over all short-term signals (1- day through 10day) and all long-term signals (40-day through 90 -day). We are able to classify $49.99 \%$ of all growth investors as momentum or contrarian (weak and strong), and $26.54 \%$ of all growth investors are best described as using the short-term signals. Only $17.36 \%$ of all growth investors appear to use the longterm signals. Value investors rely on longer-term signals. We classify 55.04\% of all value investors with $16.56 \%$ using the short-term signals and 34.3\% following the long-term signals.

In sum, not only do growth and value investors exhibit differences in the way they respond to return signals (momentum vs. contrarian behavior), but they also differ in the type of signal to which they respond. Growth investors follow short-term signals more so than longer-term signals, and value investors display the opposite tendency.

\section{Appendix B: Robustness analysis}

Our main findings show that value investors trade differently than growth investors. One important concern is that our methodology lacks statistical power, resulting in too many investors being classified as either momentum or contrarian, particularly for the weak categorization ( $\mathrm{p}$-values between $10 \%$ and $50 \%$ ). To address this, we conduct a simulation study where the return signal is randomized by randomly shuffling the actual time series of return signals used by investors to make trading decisions. By scrambling the signal and making it random, we study the performance of the classification procedure. We then classify investors as following the contrarian or momentum strategies based on the random signal. We perform 1000 repetitions and take the average across all iterations. If it is the case that investors in our dataset actually do not follow any particular strategy, then the simulated results based on a random signal should be similar to those listed in table 2. In fact, they are not, suggesting that classification performs as intended. 
Table B1 lists our results for purchases. Panel A shows the classification results for value investors. Relative to the results listed in table 2, the methodology using the random signal classifies a greater number of investors as being either strong or weak momentum investors (and a smaller number as being contrarian). Indeed, from the simulated results, it follows that if the classification procedure was random with respect to the signal, then it would appear that value investors are momentum buyers while in the actual data they are classified as contrarian. This suggests that the classification procedure used in the study is not random, and the reported results are not due to a statistical artifact. For the growth investors, the simulated results based on the scrambled signal also differ from the results with the actual data.

Panels C and D show these results more clearly. Assigning a weight of 1 to the number of momentum investors, a weight of 0 to undefined investors, and a weight of -1 for contrarian investors (as before), we compute the average investors type where values less than zero indicate a leaning toward the contrarian strategy and positive values indicate a leaning toward the momentum strategy. As mentioned, the simulated results show that value investors follow the momentum strategy when using the long-term signals and not the contrarian strategy. Moreover, using the Mantel-Haenszel test, we show that, for most simulated signals, there is no statistical difference in the strategy used by value and growth investors (panel C). We do find statistically significant differences for long horizon signals, but this is when value investors are classified as being momentum investors-in conflict with our actual results. Thus, the simulations provide additional support that the reported main results for differences between growth and value investor trading are not driven by statistical artifacts.

In panel D, the Mantel-Haenszel test is used to determine the differences between our actual results from table 2 and the simulated results. We indeed find a significant difference for both growth and value. In actual data, value investors lean much further toward the contrarian strategy and growth lean more toward the momentum strategy than found in simulation. The simulation study provides support that the value and growth agents in our sample do not trade at random. 
A second concern is that the results may be sensitive to our estimation assumptions. One such assumption is that the probabilities for observing a positive or negative return signal may be estimated using data from 1992-1999. To this, we reproduce the results from table 2 allowing the probabilities to be estimated using returns from 1997 to 1999—-the same as our sample period. Results are found in table B2. The primary results hold. There is a significant difference in the trading styles of value and growth investors. $^{30}$

Another modeling choice is our requirement of at least four buy or sell trades to be admitted into our sample. Our results do not appear to be sensitive to this choice. As seen in table B3, requiring a minimum of 10 trades, value investors tend toward contrarian investing and growth investors lean toward the momentum strategy even when the choice of filter changes.

Another concern is the possibility that the results are caused by an unusual episode in capital markets. The time period of our data, 1997 to 1999, overlaps with the beginning of the technology bubble where technology stocks, a subset of growth stocks, increased in price at a dramatic rate relative to nontechnology stocks. Though it is difficult to identify the actual beginning of the bubble, it appears clear that the bubble period contains 1999 and at least part of 1998. We briefly discuss new results from additional tests conducted to reduce this concern.

We cut the time period in half and classify investors in the time period 1997 through June 1998, eliminating much of the initial rise of the bubble. We identify 4825 growth investors who made at least four trades during this 18-month period. The results are consistent with the entire sample. For example, for the 1-day and 5-day signals, the numbers of momentum and contrarian investors are similar with 21.3\% (17.0\%) momentum (contrarian) for the 1-day signal and 20.8\% (19.4\%) for the 5-day signal. The

\footnotetext{
${ }^{30}$ Additionally, it may be useful to assume a probability of 0.5 , up signals occur as often as down signals, for all time horizons. Using the low probability of 0.5 in the test statistic when the true likelihood of observing the positive signal is much higher would lead to an over estimation of the number of momentum investors. This is what we find. In unreported results (for brevity), we find that this choice of probability greatly over classifies the number of momentum investors for both value and growth, particularly for the longer-term signals. For the 90-day signal, 77\% of value investors and $94 \%$ of growth investors are found to follow the momentum strategy (weak and strong classifications) while $3 \%$ of value and $0.7 \%$ of growth investors are classified as contrarian investors.
} 
number of momentum investors increases with the signal length with $24.7 \%$ (11.9\%) momentum (contrarian) investors at the 10-day signal, 30.5\% (8.2\%) at the 20-day signal, and so on. These results are consistent with the reported full sample results.

Ideally, our dataset would not overlap with any unusual period in capital markets. With the number of market crashes, recessions, and bubbles observed over the past 20 years, each of which affected markets for several years, it is difficult to find a period that one can deem 'normal'. We must therefore deal with the data that we have. The above tests help alleviate some of the concerns related to the power of the tests, the sensitivity to modeling choices, and the technology bubble. 


\section{References}

Banz, R.W., The relationship between return and market value of common stocks. J. Financ. Econ., 1981, 9, 3-18.

Barber, B.M. and Odean, T., Trading is hazardous to your wealth: The common stock investment performance of individual investors. J. Finance, 2000, 55, 773-806.

Barber, B.M. and Odean, T., Boys will be boys: Gender, overconfidence, and common stock investment. Q. J. Econ., 2001, 116, 261-292.

Barber, B.M. and Odean, T., Online investors: Do the slow die first? Rev. Financ. Stud., 2002, 15, 455487.

Barberis, N. and Huang, M., Mental accounting, loss aversion, and individual stock returns. J. Finance, 2001, 56, 1247-1292.

Barberis, N. and Shleifer, A., Style investing. J. Financ. Econ., 2003, 68, 161-199.

Barberis, N., Shleifer, A. and Vishny, R., A model of investor sentiment. J. Financ. Econ., 1998, 49, 307343.

Bargh, J.A., Chen, M. and Burrows, L., Automaticity of social behavior: Direct effects of trait construct and stereotype activation on action. J. Personal. Soc. Psychol., 1996, 11, 230-244.

Benjamin, D.J., Choi, J.J. and Strickland, A.J., Social identity and preferences. NBER Working Paper 13309, 2007.

Benjamin, D.J., Choi, J.J. and Fisher, G.W., Religious identity and economic behavior. NBER Working Paper 15925, 2010a.

Benjamin, D.J., Choi, J.J. and Strickland, A.J., Social identity and preferences. Am. Econ. Rev., 2010, 100, 1913-1928.

Benjamin, D.J., Choi, J.J. and Fisher, G.W., Religious identity and economic behavior. Cornell University and Yale University Working Paper, 2012. 
Benz, C., Morningstar Guide to Mutual Funds: Five Star Strategies for Success, 2005 (Wiley: New York).

Blackburn, D.W, Goetzmann, W.N. and Ukhov, A.D., Risk aversion and clientele effects. Working Paper, 2008.

Bossaerts, P. and Plott, C., Basic principles of asset pricing theory: Evidence from large-scale experimental financial markets. Rev. Finance, 2004, 8, 135-169.

Chiao, J.Y., Heck, H.E., Nakayama, K. and Ambady, N., Priming race in biracial observers affects visual search for black and white faces. Psychol. Sci., 2006, 17, 387-392.

Christiansen, C., Joensen, J.S. and Rangvid, J., Are economists more likely to hold stocks? Rev. Finance, 2008, 12, 465-496.

Cohen, J., A coefficient of agreement for nominal scales. Educ. Psychol. Measure, 1960, 20, 37-46.

Daniel, K., Hirshleifer, D. and Subrahmanyam, A., Investor psychology and security market under- and overreactions. J. Finance, 1998, 53, 1839-1886.

Deaves, R., Luders, E. and Luo, G.Y., An experimental test of the impact of overconfidence and gender on trading activity. Rev. Finance, 2009, 13, 555-575.

Dohmen, T., Falk, A., Huffman, D. and Sunde, U., Are risk aversion and impatience related to cognitive ability? Am. Econ. Rev., 2010, 100, 1238-1260.

Dorn, D. and Huberman, G., Talk and action: What individual investors say and what they do. Rev. Finance, 2005, 9, 437-481.

Durell, A., Consumer confidence and stock market returns. Working Paper, Harvard University, 1999.

Feldman, D., Production and the real rate of interest: A sample path equilibrium. Eur. Finance Rev., 2002, 6, 247-275.

Feng, L. and Seasholes, M., Do investor sophistication and trading experience eliminate behavioral biases in financial markets? Rev. Finance, 2005, 9, 305-351.

Fleiss, J.L., Statistical Methods for Rates and Proportions, ${ }^{\text {nd }}$ ed., 1981 (Wiley: New York).

Frazzini, A., The disposition effect and under-reaction to news. J. Finance, 2006, 61, 2017-2046. 
Gilad, D. and Kliger, D., Priming the risk attitudes of professionals in financial decision making. Rev. Finance, 2008, 12, 567-586.

Goetzmann, W.N. and Massa, M., Daily momentum and contrarian behavior of index fund investors. $J$. Financ. Quantit. Anal., 2002, 27, 375-389.

Goetzmann, W.N. and Massa, M., Disposition matters: Volume, volatility and price impact of behavioral bias. NBER Working Paper 9499, 2003.

Goetzmann, W. and Massa, M., Disposition matters: Volume, volatility, and price impact of a behavioral bias. J. Portfol. Mgmt, 2008, 34, 103-125.

Graham, J.R. and Kumar, A., Do dividend clienteles exist? Evidence on dividend preferences of retail investors J. Finance, 2006, 61, 1305-1336.

Grinblatt, M. and Keloharju, M., The investment behavior and performance of various investor types: A study of Finland's unique data set. J. Financ. Econ., 2000, 55, 43-67.

Grinblatt, M. and Keloharju, M., What makes investors trade? J. Finance, 2001, 56, 589-616.

Grinblatt, M., Titman, S. and Wermers, R., Momentum investment strategies, portfolio performance, and herding: A study of mutual fund behavior. Am. Econ. Rev., 1995, 85, 1088-1105.

Haigh, M.S. and List, J.A., Do professional traders exhibit myopic loss aversion? J. Finance, 2005, 60, $523-534$.

Hamilton, R.W. and Biehal, G.J., Achieving your goals or protecting their future? The effects of self-view on goals and choices J. Consum. Res., 2005, 32(2), 277-283.

Henriksson, R. and Merton, R., On market timing and investment performance. II. Statistical procedures for evaluating forecasting skills. J. Business, 1981, 54, 513-533.

Hirshleifer, D., Subrahmanyam, A. and Titman, S., Feedback and the success of irrational investors. J. Financ. Econ., 2006, 81, 311-338.

Hong, H. and Stein, J.C., A unified theory of under-reaction, momentum trading and overreaction in asset markets. J. Finance, 1999, 54, 2143-2184. 
Ivkovic, Z. and Weisbenner, S., Individual investor mutual fund flows. J. Financ. Econ., 2009, 92, 223237.

Jegadeesh, N. and Titman, S., Returns to buying winners and selling losers: Implications for stock market efficiency. J. Finance, 1993, 48, 65-91.

Kahneman, D. and Tversky, A., Prospect theory: An analysis of decision under risk. Econometrica, 1979, 47, 263-291.

Kahneman, D. and Tversky, A., Choices, values, and frames. Am. Psychol., 1984, 39, 341-350.

Kaniel, R., Saar, G. and Titman, S., Individual investor trading and stock returns. J. Finance, 2008, 63(1), 273-310.

Keim, D. and Madhaven, A., Upstairs market for large-block transactions: Analysis and measurement of price effects. Rev. Financ. Stud., 1996, 9, 1-36.

Klarman, S., Margin of Safety: Risk Averse Value Investing Strategies for the Thoughtful Investor, 1991 (Harper Collins: New York).

Kumar, A., Dynamic style preferences of individual investors and stock returns. J. Financ. Quantit. Anal., 2009, 44, 607-640.

Lakonishak, J., Shleifer, A. and Vishny, R., Contrarian investments, extrapolation and risk. J. Finance, 1994, 49, 1541-1578.

Lee, C.M.C. and Kumar, A., Retail investor sentiment and return co-movement. J. Finance, 2006, 61, 2451-2486.

Locke, P.R. and Mann, S., Professional trader discipline and trade disposition. J. Financ. Econ., 2005, 76, 401-444.

Mandel, N., Shifting selves and decision making: The effects of self-construal priming on consumer risktaking. J. Consum. Res., 2003, 30, 30-40.

Odean, T., Are investors reluctant to realize their losses? J. Finance, 1998, 53, 1775-1798.

Odean, T., Do investors trade too much? Am. Econ. Rev., 1999, 89, 1279-1297.

Pavlov, I.P., Conditional Reflexes, 1927 (G.V. Anrep, translator, 1960) (Dover: New York). 
Shefrin, H. and Statman, M., The disposition to sell winners too early and ride losers too long: Theory and evidence. J. Finance, 1985, 40, 777-790.

Shefrin, H. and Statman, M., Behavioral portfolio theory. J. Financ. Quant. Anal., 2000, 35, 127-151.

Shiller, R.J., Human behavior and the efficiency of the financial system. NBER Working Paper No. 6375, 1998.

Skinner, D. and Sloan, R., Earnings surprises, growth expectations, and stock returns or don't let an earnings torpedo sink your portfolio. Rev. Account. Stud., 2002, 7, 289-312.

Slovic, P., Psychological study of human judgment: Implications for investment decision making. J. Finance, 1972, 27, 779-99.

Statman, M., Thorley, S. and Vorkink, K., Investor overconfidence and trading volume. Rev. Financ. Stud., 2006, 19, 1531-1565.

Thaler, R., Toward a positive theory of consumer choice. J. Econ. Behav. Organiz., 1980, 1, 39-60.

Thaler, R.H., Mental accounting and consumer choice. Mktg Sci., 1985, 4, 199-214.

Thaler, R. and Johnson, E., Gambling with the house money and trying to break even: The effects of prior outcomes on risky choice. Mgmt Sci., 1990, 36, 643-660.

Trimpop, R.M., The Psychology of Risk Taking Behavior, 1994 (North-Holland: Amsterdam).

Tversky, A. and Kahneman, D., Judgment under uncertainty: Heuristics and Biases. Science, 1974, 185, $1124-1131$.

Tversky, A. and Kahneman, D., The framing of decisions and the psychology of choice. Science, 1981, 211(4481), 453-454.

Warren, C., Survey of Accounting, 2009 (Cengage Learning: Ohio). 
Table 1

Descriptive statistics. Mutual fund investors are placed into three groups: growth investors who trade only growth funds, value investors who trade only value funds, and multi-style investors who trade both growth and value funds. Mutual fund trades data are daily, for 1997-1999. No. of accounts is the number of different investors who make at least one buy or sell trade. No. of transactions is the total number of buy and sell trades of all investors. This value is then subdivided into number of purchases and number of sales. Transactions per account is the average number of trades made by each investor account. Trade size per account and Dollar trade are measures of trade size. The former is the average number of shares traded by each investor, and the latter is the average dollar value of the trade by each investor. Panel A lists the statistics for the full sample. Panel B lists the statistics for the sample of accounts with at least four trades (either buy or sell). For multi-style investors in panel B the requirement is a total of four trades in both value and growth categories together.

\begin{tabular}{|c|c|c|c|c|c|}
\hline & & \multirow{2}{*}{$\begin{array}{l}\text { Growth investors } \\
\text { Growth trades }\end{array}$} & \multirow{2}{*}{$\begin{array}{l}\text { Value investors } \\
\text { Value trades }\end{array}$} & \multicolumn{2}{|c|}{ Multi-style investors } \\
\hline & & & & Growth trades & Value trades \\
\hline \multicolumn{6}{|l|}{ Panel A: Full sample } \\
\hline No. of accounts & & 76,775 & 6705 & 3978 & 3978 \\
\hline \multirow[t]{3}{*}{ No. of transactions } & Total & 340,809 & 20,598 & 39,123 & 12,400 \\
\hline & Purchases & 251,414 & 13,101 & 29,154 & 6007 \\
\hline & Sales & 89,395 & 7497 & 9969 & 6393 \\
\hline \multirow[t]{3}{*}{ Transactions per account } & Mean & 4.44 & 3.07 & 9.83 & 3.11 \\
\hline & Median & 1.00 & 1.00 & 3.00 & 1.00 \\
\hline & St. dev & 11.98 & 9.20 & 86.06 & 9.63 \\
\hline \multirow{3}{*}{$\begin{array}{l}\text { Trade size per account } \\
\text { (in shares) }\end{array}$} & Mean & 720.97 & 610.60 & 697.41 & 522.83 \\
\hline & Median & 209.68 & 216.03 & 150.93 & 142.76 \\
\hline & St. dev & 3968.92 & 3347.22 & 4422.04 & 2918.98 \\
\hline \multirow{3}{*}{$\begin{array}{l}\text { Dollar trade per account } \\
\text { (\$) }\end{array}$} & Mean & $10,390.33$ & $13,063.75$ & $10,126.22$ & 9943.71 \\
\hline & Median & 3102.25 & 4780.00 & 2445.67 & 2668.02 \\
\hline & St. dev & $54,044.14$ & $72,227.95$ & $55,832.01$ & $52,407.45$ \\
\hline \multicolumn{6}{|c|}{ Panel B: Subsample of investors with four or more trades } \\
\hline No. of accounts & & 12,884 & 834 & 2197 & 2197 \\
\hline \multirow{3}{*}{ No. of transactions } & Total & 174,845 & 8354 & 19,613 & 7581 \\
\hline & Purchases & 134,545 & 5298 & 14,811 & 4174 \\
\hline & Sales & 40,300 & 3056 & 4802 & 3407 \\
\hline \multirow[t]{3}{*}{ Transactions per account } & Mean & 15.86 & 12.38 & 14.05 & 3.45 \\
\hline & Median & 8.00 & 7.00 & 6.00 & 2.00 \\
\hline & St. dev & 22.79 & 20.86 & 105.00 & 6.56 \\
\hline \multirow{3}{*}{$\begin{array}{l}\text { Trade size per account } \\
\text { (in shares) }\end{array}$} & Mean & 818.88 & 843.97 & 746.92 & 529.15 \\
\hline & Median & 59.64 & 52.81 & 114.99 & 114.94 \\
\hline & St. dev & 6235.22 & 6849.61 & 4741.82 & 2746.21 \\
\hline \multirow{3}{*}{$\begin{array}{l}\text { Dollar trade per account } \\
\text { (\$) }\end{array}$} & Mean & $11,675.91$ & $18,142.28$ & $10,663.54$ & $10,374.46$ \\
\hline & Median & 876.42 & 1238.13 & 1924.73 & 2245.13 \\
\hline & St. dev & $88,742.48$ & $154,123.80$ & $58,958.77$ & $53,004.53$ \\
\hline
\end{tabular}


Table 2

Trading classification for purchases. We use a binomial classification to classify value investors and growth investors as being momentum buyers, contrarian buyers and undefined for various past return signals. A momentum (contrarian) investor tends to purchase after a positive (negative) return signal, a price increase (decline). There are seven return signals: 1-day, 5-day, 10-day, 20-day, 40-day, 60-day, and 90-day. Investors are said to follow a momentum (contrarian) strategy if the number of trades following a positive (negative) return signal is greater than expected assuming randomly distributed trades. Strong classification indicates significance at the $10 \%$ level (less than 10\% chance of observing the trading pattern by chance) and weak refers to significance levels between $10 \%$ and $50 \%$. The values in the table are the percent of investors who fit the classification. Panel C gives the average investor type for each signal. We give a weight of +1 to momentum traders, -1 to contrarian traders and 0 to undefined investors. Positive (negative) values indicate the average investor follows a momentum (contrarian) strategy. The Mantel-Haenszel chi-square statistic tests if the average value investor is equal to the average growth investor.

\begin{tabular}{|c|c|c|c|c|c|c|c|c|}
\hline & Signal & 1-day & 5-day & 10-day & 20-day & 40-day & 60-day & 90-day \\
\hline \multicolumn{9}{|c|}{ Panel A: Value trader purchases } \\
\hline Strong Momentum & $\alpha<0.1$ & 1.94 & 1.79 & 0.60 & 0.60 & 1.34 & 2.24 & 3.43 \\
\hline Weak Momentum & $p .5>a>0.1$ & 14.03 & 12.84 & 10.00 & 8.36 & 8.51 & 6.57 & 6.72 \\
\hline Undefined & & 51.94 & 57.76 & 48.06 & 69.10 & 61.49 & 50.00 & 43.88 \\
\hline Weak Contrarian & $0.5>\alpha>0.1$ & 26.42 & 20.45 & 28.66 & 15.82 & 17.31 & 19.40 & 9.85 \\
\hline Strong Contrarian & $\alpha<0.1$ & 5.67 & 7.16 & 12.69 & 6.12 & 11.34 & 21.79 & 36.12 \\
\hline \multicolumn{9}{|c|}{ Panel B: Growth trader purchases } \\
\hline Strong Momentum & $\alpha<0.1$ & 5.35 & 4.35 & 3.57 & 4.83 & 7.05 & 9.80 & 16.01 \\
\hline Weak Momentum & $0.5>\alpha>0.1$ & 15.90 & 15.69 & 17.71 & 20.42 & 20.91 & 26.68 & 38.42 \\
\hline Undefined & & 58.45 & 60.10 & 64.91 & 64.10 & 64.66 & 59.49 & 43.06 \\
\hline Weak Contrarian & $0.5>\alpha>0.1$ & 15.71 & 14.52 & 11.07 & 8.43 & 4.44 & 3.02 & 1.95 \\
\hline Strong Contrarian & $\alpha<0.1$ & 4.59 & 5.34 & 2.74 & 2.22 & 2.95 & 1.02 & 0.56 \\
\hline \multicolumn{9}{|c|}{ Panel C: Comparison of growth and value investors } \\
\hline Value investor & Average & -0.161 & -0.130 & -0.307 & -0.130 & -0.188 & -0.324 & -0.358 \\
\hline Growth investor & Average & 0.010 & 0.002 & 0.075 & 0.146 & 0.206 & 0.324 & 0.519 \\
\hline Mantel-Haenszel & $\begin{array}{c}\text { Chi-sq } \\
p \text {-Value }\end{array}$ & $\begin{array}{l}44.10 \\
(0.0001)\end{array}$ & $\begin{array}{l}27.48 \\
(0.0001)\end{array}$ & $\begin{array}{l}250.27 \\
(0.0001)\end{array}$ & $\begin{array}{l}140.16 \\
(0.0001)\end{array}$ & $\begin{array}{l}275.36 \\
(0.0001)\end{array}$ & $\begin{array}{l}636.70 \\
(0.0001)\end{array}$ & $\begin{array}{l}968.93 \\
(0.0001)\end{array}$ \\
\hline
\end{tabular}


Table 3

Trading classification for sells. We use a binomial classification to classify value investors and growth investors as being momentum sellers, contrarian sellers and undefined for various past return signals. A momentum (contrarian) investor tends to sell after a negative (positive) return signal, a price decline (increase). There are seven return signals: 1-day, 5-day, 10-day, 20-day, 40-day, 60-day, and 90-day. Investors are said to follow a momentum (contrarian) selling strategy if the number of sales following a negative (positive) return signal is greater than expected assuming randomly distributed trades. Strong classification indicates

significance at the $10 \%$ level (less than $10 \%$ chance of observing the trading pattern by chance) and weak refers to significance levels between $10 \%$ and $50 \%$. The values in the table are the percent of investors who fit the classification. Panel C gives the average investor type for each signal. We give a value of +1 to momentum traders, -1 to contrarian traders and 0 to undefined investors. The average, therefore, describes whether the style investors lean to one type of trading strategy - a positive value indicates that the average investor is momentum and a negative value indicates that the average investor is contrarian. The MantelHaenszel chi-square statistic tests if the average value investor is equal to the average growth investor.

\begin{tabular}{|c|c|c|c|c|c|c|c|c|}
\hline & Signal & 1-day & 5-day & 10-day & 20-day & 40-day & 60-day & 90-day \\
\hline \multicolumn{9}{|c|}{ Panel A: Value trader sells } \\
\hline Strong Contrarian & $a<0.1$ & 2.56 & 1.50 & 1.07 & 2.56 & 0.85 & 1.28 & 0.85 \\
\hline Weak Contrarian & $0.5>\alpha>0.1$ & 13.46 & 12.39 & 9.62 & 10.68 & 17.74 & 10.90 & 4.49 \\
\hline Undefined & & 51.07 & 54.06 & 48.72 & 60.26 & 59.62 & 56.62 & 40.38 \\
\hline Weak Momentum & $0.5>\alpha>0.1$ & 25.21 & 24.57 & 29.70 & 21.15 & 15.38 & 19.02 & 19.66 \\
\hline Strong Momentum & $\alpha<0.1$ & 7.69 & 7.48 & 10.90 & 5.34 & 6.41 & 12.18 & 34.62 \\
\hline \multicolumn{9}{|c|}{ Panel B: Growth trader sells } \\
\hline Strong Contrarian & $\alpha<0.1$ & 3.25 & 3.23 & 2.00 & 3.78 & 4.93 & 5.47 & 8.41 \\
\hline Weak Contrarian & $0.5>\alpha>0.1$ & 15.77 & 17.75 & 18.33 & 23.11 & 16.13 & 21.42 & 28.56 \\
\hline Undefined & & 55.88 & 55.18 & 58.07 & 57.85 & 67.04 & 65.20 & 59.15 \\
\hline Weak Momentum & $0.5>\alpha>0.1$ & 23.29 & 21.72 & 20.00 & 14.21 & 9.85 & 6.62 & 3.46 \\
\hline Strong Momentum & $\alpha<0.1$ & 1.82 & 2.11 & 1.60 & 1.05 & 2.05 & 1.29 & 0.42 \\
\hline \multicolumn{9}{|c|}{ Panel C: Comparison of growth and value investors } \\
\hline Value investor & Average & 0.169 & 0.182 & 0.299 & 0.132 & 0.032 & 0.190 & 0.489 \\
\hline Growth investor & Average & 0.061 & 0.028 & 0.013 & -0.116 & -0.091 & -0.190 & -0.331 \\
\hline Mantel-Haenszel & $\begin{array}{c}\text { Chi-sq } \\
p \text {-Value }\end{array}$ & $\begin{array}{l}11.98 \\
(0.001)\end{array}$ & $\begin{array}{l}23.06 \\
(0.0001)\end{array}$ & $\begin{array}{l}85.97 \\
(0.0001)\end{array}$ & $\begin{array}{l}65.75 \\
(0.0001)\end{array}$ & $\begin{array}{l}18.91 \\
(0.0001)\end{array}$ & $\begin{array}{c}173.22 \\
(0.0001)\end{array}$ & $\begin{array}{l}669.20 \\
(0.0001)\end{array}$ \\
\hline
\end{tabular}


Table 4

Trading classification of multi-style investors. This table shows the trading strategies of investors who trade both value and growth given in terms of percentages of total number of investors. The columns identify the past return signal used. There are seven return signals: 1-day, 5-day, 10-day, 20-day, 40-day, 60-day, and 90-day. We use binomial classification. The rows identify the strategy used by investors-Momentum/Contrarian identifies those investors who follow a momentum growth strategy but a contrarian value strategy. Undetermined includes those investors not classified as contrarian and/or momentum. We test for agreement in trading strategy by computing the Kappa coefficient. The p-value provided is the exact probability that the Kappa coefficient is zero-representing no agreement in two trading strategies. The closer Kappa is to unity, the greater the agreement (values above 0.4 indicate moderate agreement). The log odds ratio test compares the number of individuals who trade consistently across the two styles with those who trade inconsistently. The value ranges from zero (no agreement) to infinity (complete agreement). The McNemar test is used to test whether the same number of value investors is classified as momentum as are growth investors, and the same number of value-contrarian as are growth-contrarian. The test is applied to a $2 \square 2$ contingency table, where the columns are Growth Momentum and Growth Contrarian, and the rows are Value Momentum and Value Contrarian. The cells contain the number of investors in each category. The test effectively compares the size of the off-diagonal cells. Test statistic is computed as: Q= (Mom|Contra-Contra| Mom)2/(Mom|Contra+Contra|Mom) and it follows a chi-squared distribution. Statistical rejection implies that there is a significantly larger group of buyers who are Mom|Contr compared with Contr|Mom, and there is a significantly larger group of sellers who are Contr|Mom compared with Mom|Contr. Statistical rejection implies rejection of consistency.

\begin{tabular}{|c|c|c|c|c|c|c|c|}
\hline Growth/Value & 1-day & 5-day & 10-day & 20-day & 40-day & 60-day & 90-day \\
\hline \multicolumn{8}{|l|}{ Panel A: Buys } \\
\hline Momentum/Momentum & 1.23 & 3.13 & 3.27 & 4.15 & 0.82 & 1.23 & 2.25 \\
\hline Contrarian/Momentum & 0.54 & 1.09 & 0.61 & 0.48 & 0.14 & 0.34 & 0.07 \\
\hline Momentum/Contrarian & 8.78 & 6.54 & 5.04 & 4.63 & 2.31 & 2.93 & 6.47 \\
\hline Contrarian/Contrarian & 15.52 & 10.69 & 9.87 & 5.38 & 3.68 & 2.65 & 0.61 \\
\hline Undetermined & 73.93 & 78.56 & 81.21 & 85.36 & 93.06 & 92.85 & 90.61 \\
\hline Log odds ratio & 0.60 & 0.67 & 1.02 & 1.01 & 0.98 & 0.51 & 0.50 \\
\hline$p$-Value & $(0.086)$ & $(0.017)$ & $(0.005)$ & $(0.010)$ & $(0.109)$ & $(0.176)$ & $(0.322)$ \\
\hline Kappa & 0.105 & 0.134 & 0.355 & 0.350 & 0.240 & 0.162 & 0.030 \\
\hline$p$-Value & $(0.001)$ & $(0.003)$ & $(0.000)$ & $(0.000)$ & $(0.001)$ & $(0.022)$ & $(0.242)$ \\
\hline McNemar & 106.87 & 57.14 & 50.90 & 49.61 & 28.44 & 30.08 & 92.04 \\
\hline$p$-Value & $(0.0001)$ & $(0.0001)$ & $(0.0001)$ & $(0.0001)$ & $(0.0001)$ & $(0.0001)$ & $(0.0001)$ \\
\hline \multicolumn{8}{|l|}{ Panel B: Sells } \\
\hline Momentum/Momentum & 13.97 & 9.48 & 11.88 & 7.88 & 5.79 & 1.90 & 1.10 \\
\hline Contrarian/Momentum & 3.49 & 3.79 & 8.88 & 3.49 & 1.00 & 1.70 & 3.69 \\
\hline Momentum/Contrarian & 2.99 & 2.40 & 3.19 & 2.40 & 0.10 & 0.10 & 0.00 \\
\hline Contrarian/Contrarian & 1.30 & 1.70 & 1.00 & 2.20 & 1.00 & 1.50 & 1.60 \\
\hline Undetermined & 78.24 & 82.63 & 75.05 & 84.03 & 92.12 & 94.81 & 93.61 \\
\hline Log odds ratio & 0.24 & 0.25 & -0.38 & 0.32 & 1.76 & 1.22 & 0.73 \\
\hline$p$-Value & $(0.266)$ & $(0.252)$ & $(0.835)$ & $(0.189)$ & $(0.055)$ & $(0.130)$ & $(0.250)$ \\
\hline Kappa & 0.098 & 0.115 & -0.123 & 0.160 & 0.567 & 0.364 & 0.111 \\
\hline$p$-Value & $(0.108)$ & $(0.088)$ & $(0.015)$ & $(0.032)$ & $(0.000)$ & $(0.001)$ & $(0.081)$ \\
\hline McNemar & 0.38 & 3.16 & 26.85 & 2.05 & 7.36 & 14.22 & 35.10 \\
\hline$p$-Value & $(0.540)$ & $(0.083)$ & $(0.0001)$ & $(0.156)$ & $(0.013)$ & $(0.001)$ & $(0.0001)$ \\
\hline
\end{tabular}


Table A1

Investor classification by signal horizon: Buys. We classify all investors as strong contrarian, weak contrarian, undefined, weak momentum, and strong momentum using binomial classification (the same methods as described in tables 2 and 3 ) according to their buying history. A momentum (contrarian) investor tends to purchase after a positive (negative) return signal, a price increase (decline). There are seven return signals: 1-day, 5-day, 10-day, 20-day, 40-day, 60-day, and 90day. Investors are said to follow a momentum (contrarian) strategy if the number of trades following a positive (negative) return signal is greater than expected assuming randomly distributed trades. We then classify each investor according to the return signal that best describes their trading pattern. For each investor in the dataset we determine the signal length (1-day, 5-day, etc.) that results in the lowest p-value in the binomial classification method (the return signal that minimized the p-value of the binomial distribution). Values in the table are percentages of the total population.

\begin{tabular}{|c|c|c|c|c|c|c|c|c|}
\hline & Row sum & 1-day & 5-day & 10-day & 20-day & 40-day & 60-day & 90-day \\
\hline \multicolumn{9}{|c|}{ Panel A: Value trader buys } \\
\hline Str. Contr. & 44.84 & 2.64 & 3.00 & 5.28 & 2.04 & 0.84 & 6.12 & 24.94 \\
\hline Wk. Contr. & 19.42 & 2.88 & 1.44 & 3.96 & 2.88 & 1.32 & 1.68 & 5.28 \\
\hline Undefined & 21.46 & & & & & & & \\
\hline Wk. Mom. & 9.23 & 3.12 & 2.52 & 0.84 & 0.96 & 0.72 & 0.36 & 0.72 \\
\hline Str. Mom. & 5.04 & 0.24 & 1.08 & 0.12 & 0.24 & 0.24 & 0.72 & 2.40 \\
\hline Column sum & 100.00 & 8.87 & 8.03 & 10.19 & 6.12 & 3.12 & 8.87 & 33.33 \\
\hline \multicolumn{9}{|c|}{ Panel B: Growth trader buys } \\
\hline Str. Contr. & 12.43 & 3.02 & 3.60 & 1.40 & 1.40 & 1.85 & 0.75 & 0.41 \\
\hline Wk. Contr. & 22.90 & 6.84 & 3.90 & 3.17 & 3.58 & 2.27 & 1.91 & 1.23 \\
\hline Undefined & 9.52 & & & & & & & \\
\hline Wk. Mom. & 31.61 & 5.84 & 5.21 & 5.22 & 3.86 & 3.20 & 3.80 & 4.49 \\
\hline Str. Mom. & 23.54 & 3.58 & 1.97 & 1.23 & 1.72 & 1.51 & 2.93 & 10.60 \\
\hline Column sum & 100.00 & 19.27 & 14.68 & 11.02 & 10.56 & 8.82 & 9.39 & 16.73 \\
\hline
\end{tabular}


Table A2

Investor classification by signal horizon: Sells. We classify all investors as strong contrarian, weak contrarian, undefined, weak momentum, and strong momentum using binomial classification (the same methods as described in tables 2 and 3) according to their selling history. A momentum (contrarian) investor tends to sell after a negative (positive) return signal, a price decline (increase). There are seven return signals: 1-day, 5-day, 10-day, 20-day, 40-day, 60-day, and 90-day. Investors are said to follow a momentum (contrarian) strategy if the number of trades following a positive (negative) return signal is greater than expected

assuming randomly distributed trades. We then classify each investor according to the return signal that best describes their trading pattern. For each investor in the dataset we determine the signal length (1-day, 5-day, etc.) that results in the lowest p-value in the binomial classification method (the return signal that minimized the p-value of the binomial distribution). Values in the table are percentages of the total population.

\begin{tabular}{|c|c|c|c|c|c|c|c|c|}
\hline & Row sum & 1-day & 5-day & 10-day & 20-day & 40-day & 60-day & 90-day \\
\hline \multicolumn{9}{|c|}{ Panel A: Value trader sells } \\
\hline Str. Contr. & 3.00 & 0.96 & 0.48 & 0.24 & 0.60 & 0.24 & 0.24 & 0.24 \\
\hline Wk. Contr. & 6.12 & 0.96 & 1.32 & 0.72 & 0.96 & 1.20 & 0.72 & 0.24 \\
\hline Undefined & 44.96 & & & & & & & \\
\hline Wk. Mom. & 18.71 & 1.32 & 1.08 & 3.00 & 1.56 & 0.36 & 1.44 & 9.95 \\
\hline Str. Mom. & 27.22 & 2.64 & 1.56 & 2.28 & 1.08 & 0.72 & 1.56 & 17.39 \\
\hline Column sum & 100.00 & 5.88 & 4.44 & 6.24 & 4.20 & 2.52 & 3.96 & 27.82 \\
\hline \multicolumn{9}{|c|}{ Panel B: Growth trader sells } \\
\hline Str. Contr. & 8.11 & 1.43 & 0.78 & 0.41 & 0.72 & 0.67 & 0.89 & 3.21 \\
\hline Wk. Contr. & 16.23 & 4.94 & 3.45 & 2.23 & 1.88 & 1.47 & 1.33 & 0.92 \\
\hline Undefined & 50.01 & & & & & & & \\
\hline Wk. Mom. & 21.66 & 4.57 & 2.70 & 3.97 & 3.07 & 2.91 & 2.43 & 2.00 \\
\hline Str. Mom. & 3.99 & 0.65 & 0.76 & 0.64 & 0.43 & 0.78 & 0.54 & 0.19 \\
\hline Column sum & 100.00 & 11.59 & 7.70 & 7.25 & 6.10 & 5.84 & 5.19 & 6.33 \\
\hline
\end{tabular}


Table B1

Trading classification for purchases_-simulation. We reproduce table 2 using a simulation approach whereby value investors and growth investors are classified as being momentum buyers, contrarian buyers and undefined for various past return signals. For the simulation, we randomly shuffle the actual return signal and classify all investors with respect to the random signal. The values in panels A and B are the average fraction of investors classified in each category over 1000 iterations for the seven return signals. Panel C reports the average strategy type by assigning strong and weak momentum a weight of 1 , undefined a weight of 0 , and weak and strong contrarian a weight of -1 . Positive (negative) values indicate the average investor follows a momentum (contrarian) strategy. The MantelHaenszel chi-square statistic tests if the average strategy used by value investors is equal to the average strategy used by growth investors. Panel D reports the Mantel-Haenszel test statistics for the differences between our actual results from table 2 and the simulated results.

\begin{tabular}{|c|c|c|c|c|c|c|c|c|}
\hline & Signal & 1-day & 5-day & 10-day & 20-day & 40-day & 60-day & 90-day \\
\hline \multicolumn{9}{|c|}{ Panel A: Value trader purchases } \\
\hline Strong Momentum & $\alpha<0.1$ & 4.56 & 3.78 & 3.69 & 3.49 & 2.22 & 1.89 & 1.97 \\
\hline Weak Momentum & $0.5>\alpha>0.1$ & 14.92 & 14.81 & 15.47 & 17.82 & 15.56 & 16.63 & 18.64 \\
\hline Undefined & & 57.24 & 59.21 & 59.83 & 65.21 & 71.60 & 72.12 & 71.14 \\
\hline Weak Contrarian & $0.5>\alpha>0.1$ & 18.65 & 17.43 & 16.52 & 8.49 & 5.87 & 4.78 & 3.27 \\
\hline Strong Contrarian & $\alpha<0.1$ & 4.60 & 4.76 & 4.47 & 4.98 & 4.75 & 4.58 & 4.99 \\
\hline \multicolumn{9}{|c|}{ Panel B: Growth trader purchases } \\
\hline Strong Momentum & $\alpha<0.1$ & 5.02 & 4.05 & 3.25 & 3.40 & 2.64 & 2.20 & 2.02 \\
\hline Weak Momentum & $0.5>\alpha>0.1$ & 14.73 & 14.85 & 14.45 & 16.36 & 15.87 & 19.68 & 20.47 \\
\hline Undefined & & 61.28 & 61.20 & 65.90 & 67.26 & 72.52 & 71.54 & 72.02 \\
\hline Weak Contrarian & $0.5>\alpha>0.1$ & 14.57 & 14.60 & 12.01 & 8.29 & 3.51 & 1.94 & 0.88 \\
\hline Strong Contrarian & $\alpha<0.1$ & 4.40 & 5.30 & 4.39 & 2.22 & 5.46 & 4.63 & 4.59 \\
\hline \multicolumn{9}{|c|}{ Panel C: Comparison of growth and value investors } \\
\hline Value investor simulated & Average & -0.037 & -0.036 & -0.018 & 0.079 & 0.072 & 0.091 & 0.124 \\
\hline Growth investor simulated & Average & 0.008 & -0.010 & 0.013 & 0.068 & 0.095 & 0.153 & 0.170 \\
\hline Mantel-Haenszel & $\begin{array}{l}\text { Chi-sq } \\
p \text {-Value }\end{array}$ & $\begin{array}{l}3.31 \\
(0.069)\end{array}$ & $\begin{array}{l}1.22 \\
(0.269)\end{array}$ & $\begin{array}{l}1.75 \\
(0.185)\end{array}$ & $\begin{array}{l}0.52 \\
(0.469)\end{array}$ & $\begin{array}{l}1.35 \\
(0.245)\end{array}$ & $\begin{array}{l}8.97 \\
(0.003)\end{array}$ & $\begin{array}{l}5.39 \\
(0.020)\end{array}$ \\
\hline \multicolumn{9}{|c|}{ Panel D: Comparison of actual and simulated results } \\
\hline Value actual & Average & -0.161 & -0.130 & -0.307 & -0.130 & -0.188 & -0.324 & -0.358 \\
\hline Value simulated & Average & -0.037 & -0.036 & -0.018 & 0.079 & 0.072 & 0.091 & 0.124 \\
\hline Mantel-Haenszel & $\begin{array}{l}\text { Chi-sq } \\
p \text {-Value }\end{array}$ & $\begin{array}{c}13.1786 \\
(0.0003)\end{array}$ & $\begin{array}{c}7.0364 \\
(0.008)\end{array}$ & $\begin{array}{l}60.8391 \\
(0.0001)\end{array}$ & $\begin{array}{c}40.3759 \\
(0.0001)\end{array}$ & $\begin{array}{l}64.7173 \\
(0.0001)\end{array}$ & $\begin{array}{c}167.2314 \\
(0.0001)\end{array}$ & $\begin{array}{r}183.8807 \\
(0.0001)\end{array}$ \\
\hline Growth actual & Average & 0.010 & 0.002 & 0.075 & 0.146 & 0.206 & 0.324 & 0.519 \\
\hline Growth simulated & Average & 0.008 & -0.010 & 0.013 & 0.068 & 0.095 & 0.153 & 0.170 \\
\hline Mantel-Haenszel & $\begin{array}{l}\text { Chi-sq } \\
p \text {-Value }\end{array}$ & $\begin{array}{l}0.03 \\
(0.854)\end{array}$ & $\begin{array}{l}2.06 \\
(0.151)\end{array}$ & $\begin{array}{l}65.86 \\
(0.0001)\end{array}$ & $\begin{array}{c}108.69 \\
(0.0001)\end{array}$ & $\begin{array}{l}247.86 \\
(0.0001)\end{array}$ & $\begin{array}{l}607.21 \\
(0.0001)\end{array}$ & $\begin{array}{l}2368.95 \\
\quad(0.0001)\end{array}$ \\
\hline
\end{tabular}


Table B2

Trading classification for purchases-Choice of probability. We reproduce table 2 to show the sensitivity of our results to the choice of return signal probability. The probability of observing a positive signal is determined from return data from 1997-1999. Value and growth investors are classified as being momentum buyers, contrarian buyers and undefined for various past return signals. Investors are said to follow a momentum (contrarian) strategy if the number of trades following a positive (negative) return signal is greater than expected assuming randomly distributed trades. Strong classification indicates significant at the $10 \%$ level and weak refers to significant levels between $10 \%$ and $50 \%$. The values in the table are the percent of investors who fit the classification. Panel C gives the average investor type for each signal. We give a value of +1 to momentum traders, -1 to contrarian traders and 0 to undefined investors. Positive (negative) values indicate the average investor follows a momentum (contrarian) strategy. The Mantel-Haenszel chi-square statistic tests if the average value investor is equal to the average growth investor.

\begin{tabular}{|c|c|c|c|c|c|c|c|c|}
\hline & Signal & 1-day & 5-day & 10-day & 20-day & 40-day & 60 -day & 90-day \\
\hline \multicolumn{9}{|c|}{ Panel A: Value trader purchases } \\
\hline Strong Momentum & $\alpha<0.1$ & 1.68 & 1.68 & 0.48 & 0.60 & 0.96 & 1.32 & 2.16 \\
\hline Weak Momentum & $0.5>\alpha>0.1$ & 11.27 & 10.19 & 8.39 & 6.47 & 4.32 & 5.88 & 5.76 \\
\hline Undefined & & 44.00 & 47.72 & 38.49 & 56.47 & 55.28 & 42.93 & 35.25 \\
\hline Weak Contrarian & $0.5>\alpha>0.1$ & 19.42 & 15.59 & 23.14 & 12.47 & 8.39 & 10.07 & 3.36 \\
\hline Strong Contrarian & $\alpha<0.1$ & 4.08 & 5.28 & 9.95 & 4.44 & 11.51 & 20.26 & 33.93 \\
\hline \multicolumn{9}{|c|}{ Panel B: Growth trader purchases } \\
\hline Strong Momentum & $\alpha<0.1$ & 4.36 & 3.42 & 2.42 & 3.94 & 2.86 & 1.23 & 0.60 \\
\hline Weak Momentum & $0.5>\alpha>0.1$ & 13.84 & 13.57 & 14.36 & 17.49 & 17.84 & 11.34 & 9.09 \\
\hline Undefined & & 52.33 & 57.40 & 62.90 & 62.06 & 65.19 & 73.46 & 73.54 \\
\hline Weak Contrarian & $0.5>\alpha>0.1$ & 16.08 & 12.67 & 9.41 & 6.06 & 1.51 & 0.61 & 0.00 \\
\hline Strong Contrarian & $\alpha<0.1$ & 5.69 & 5.23 & 3.21 & 2.76 & 4.91 & 5.67 & 9.07 \\
\hline \multicolumn{9}{|c|}{ Panel C: Comparison of growth and value investors } \\
\hline Value investor & Average & -0.13 & -0.11 & -0.30 & -0.12 & -0.18 & -0.29 & -0.37 \\
\hline Growth investor & Average & -0.04 & -0.01 & 0.05 & 0.14 & 0.15 & 0.07 & 0.01 \\
\hline Mantel-Haenszel & $\begin{array}{c}\text { Chi-sq } \\
p \text {-Value }\end{array}$ & $\begin{array}{l}12.56 \\
(0.0004)\end{array}$ & $\begin{array}{l}17.37 \\
(0.0001)\end{array}$ & $\begin{array}{l}231.49 \\
(0.0001)\end{array}$ & $\begin{array}{l}136.75 \\
(0.0001)\end{array}$ & $\begin{array}{l}260.42 \\
(0.0001)\end{array}$ & $\begin{array}{l}372.88 \\
(0.0001)\end{array}$ & $\begin{array}{l}395.01 \\
(0.0001)\end{array}$ \\
\hline
\end{tabular}


Table B3

Trading classification for purchases-Choice of filter. We reproduce table 2 to show the sensitivity of our results to the choice of data filter. For this table, we require investors to make a minimum of 10 trades to be included in the sample. Value and growth investors are classified as being momentum buyers, contrarian buyers and undefined for various past return signals. Investors are said to follow a momentum (contrarian) strategy if the number of trades following a positive (negative) return signal is greater than expected assuming randomly distributed trades. Strong classification indicates significant at the $10 \%$ level and weak refers to significant levels between $10 \%$ and $50 \%$. The values in the table are the percent of investors who fit the classification. Panel C gives the average investor type for each signal. We give a value of +1 to momentum traders, -1 to contrarian traders and 0 to undefined investors. Positive (negative) values indicate the average investor follows a momentum (contrarian) strategy. The Mantel-Haenszel chi-square statistic tests if the average value investor is equal to the average growth investor.

\begin{tabular}{|c|c|c|c|c|c|c|c|c|}
\hline & Signal & 1-day & 5-day & 10-day & 20-day & 40-day & 60-day & 90-day \\
\hline \multicolumn{9}{|c|}{ Panel A: Value trader purchases } \\
\hline Strong Momentum & $\alpha<0.1$ & 2.82 & 2.02 & 0.40 & 1.21 & 2.82 & 4.03 & 6.85 \\
\hline Weak Momentum & $0.5>a>0.1$ & 8.47 & 4.44 & 1.61 & 2.42 & 3.23 & 3.23 & 4.84 \\
\hline Undefined & & 48.79 & 64.11 & 54.03 & 78.63 & 79.44 & 71.37 & 63.31 \\
\hline Weak Contrarian & $0.5>a>0.1$ & 29.03 & 17.34 & 23.39 & 6.85 & 2.82 & 1.61 & 2.02 \\
\hline Strong Contrarian & $\alpha<0.1$ & 10.89 & 12.10 & 20.56 & 10.89 & 11.69 & 19.76 & 22.98 \\
\hline \multicolumn{9}{|c|}{ Panel B: Growth trader purchases } \\
\hline Strong Momentum & $\alpha<0.1$ & 6.40 & 6.76 & 5.46 & 7.08 & 10.45 & 15.93 & 25.24 \\
\hline Weak Momentum & $0.5>a>0.1$ & 10.41 & 8.66 & 10.16 & 8.95 & 12.81 & 18.65 & 25.47 \\
\hline Undefined & & 65.84 & 69.05 & 76.42 & 79.22 & 72.48 & 63.42 & 48.38 \\
\hline Weak Contrarian & $0.5>a>0.1$ & 11.27 & 8.89 & 4.74 & 2.11 & 0.49 & 0.34 & 0.15 \\
\hline Strong Contrarian & $\alpha<0.1$ & 6.09 & 6.64 & 3.22 & 2.65 & 3.77 & 1.66 & 0.76 \\
\hline \multicolumn{9}{|c|}{ Panel C: Comparison of growth and value investors } \\
\hline Value investor & Average & -0.29 & -0.23 & -0.42 & -0.14 & -0.08 & -0.14 & -0.13 \\
\hline Growth investor & Average & -0.01 & 0.00 & 0.08 & 0.11 & 0.19 & 0.33 & 0.50 \\
\hline Mantel-Haenszel & $\begin{array}{c}\text { Chi-sq } \\
p \text {-Value }\end{array}$ & $\begin{array}{l}53.48 \\
(0.0001)\end{array}$ & $\begin{array}{l}39.75 \\
(0.0001)\end{array}$ & $\begin{array}{l}239.82 \\
(0.0001)\end{array}$ & $\begin{array}{l}67.97 \\
(0.0001)\end{array}$ & $\begin{array}{l}74.24 \\
(0.0001)\end{array}$ & $\begin{array}{l}191.71 \\
(0.0001)\end{array}$ & $\begin{array}{l}326.12 \\
(0.0001)\end{array}$ \\
\hline
\end{tabular}


Figure 1

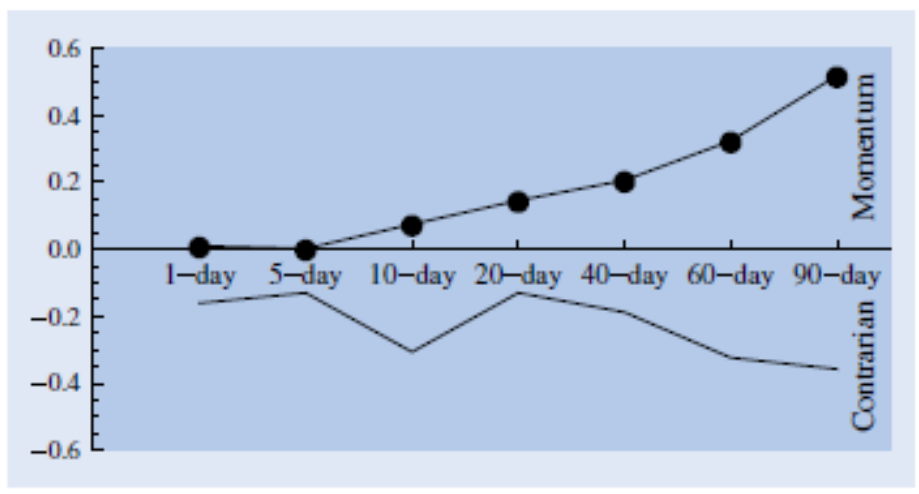

Fig. 1. Average investor type-Purchases. The average investor types from table 2 are plotted. Value investors (solid line) and growth investors (line with $\bullet$ ) are classified as contrarian or momentum traders according to their purchasing behavior. We give a weight of +1 to momentum traders, -1 to contrarian traders and 0 to undefined investors. Positive (negative) values indicate the average investor follows a momentum (contrarian) strategy. The figure plots the average investor type for growth and value style investors for 10 different return signals. A positive value indicates that the average investor is momentum and a negative value indicates that the average investor is contrarian. 
Figure 2

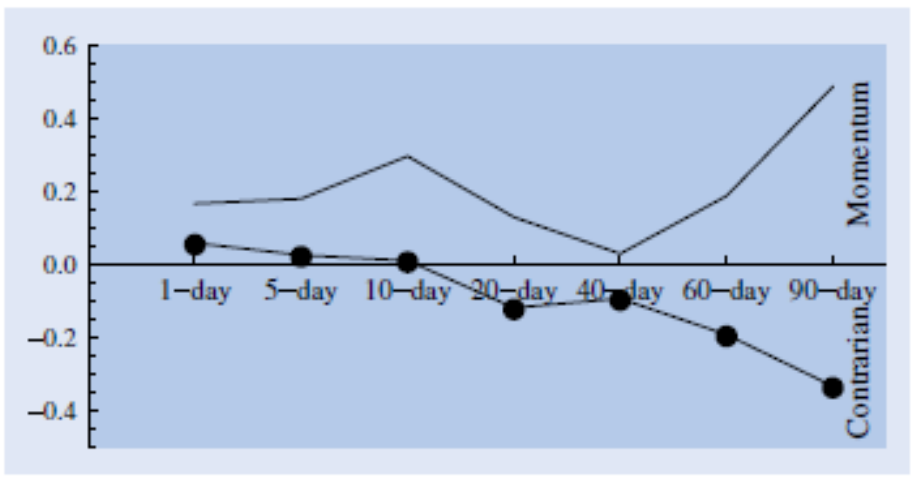

Fig 2. Average investor type-Sells. The average investor types from table 3 are plotted. Value investors (solid line) and growth investors (line with $\bullet$ ) are classified as contrarian or momentum traders according to their selling behavior. We give a weight of +1 to momentum traders, -1 to contrarian traders and 0 to undefined investors. Positive (negative) values indicate the average investor follows a momentum (contrarian) strategy. The figure plots the average investor type for growth and value style investors for 10 different return signals. A positive value indicates that the average investor is momentum and a negative value indicates that the average investor is contrarian. 
Figure 3

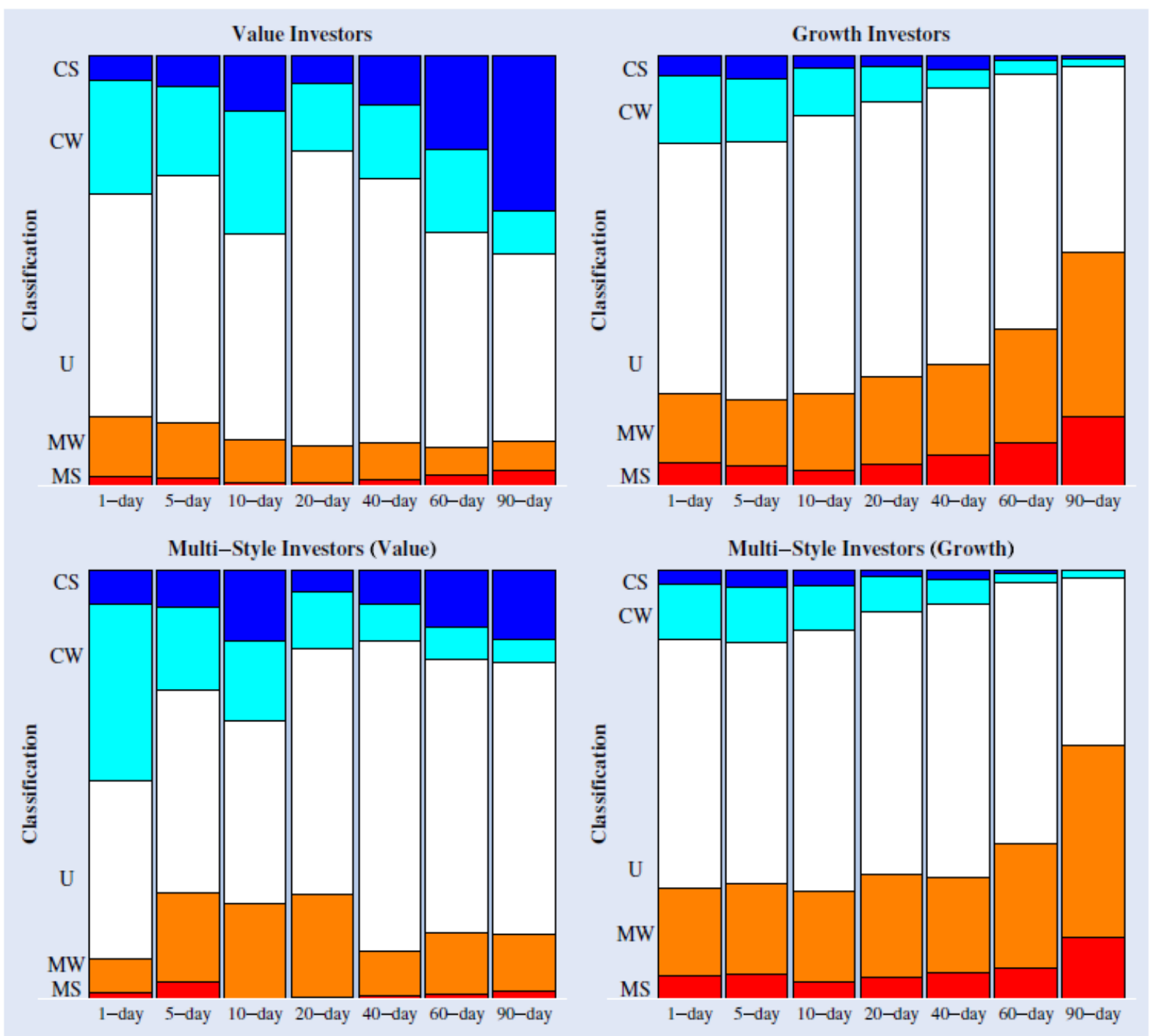

Fig 3. Investor types and return signal—Buys. The chart in each panel shows the distribution of different investors for various past return signals. We classify value investors, growth investors, and multi-style investors who trade in value and in growth funds as being momentum buyers, contrarian buyers and undefined. The categories on the $\mathrm{X}$-axis correspond to the different lengths of the prior return signal, from the return over the previous one day (1-day), five trading days (5-day) —a week, through the return over the previous 90 trading days (90-day). The Y-axis is the proportion of investors classified into one of the five categories (from bottom to top): Momentum Strong (MS), Momentum Weak (MW), Unclassified (U), Contrarian Weak (CW), and Contrarian Strong (CS). 
Figure 4

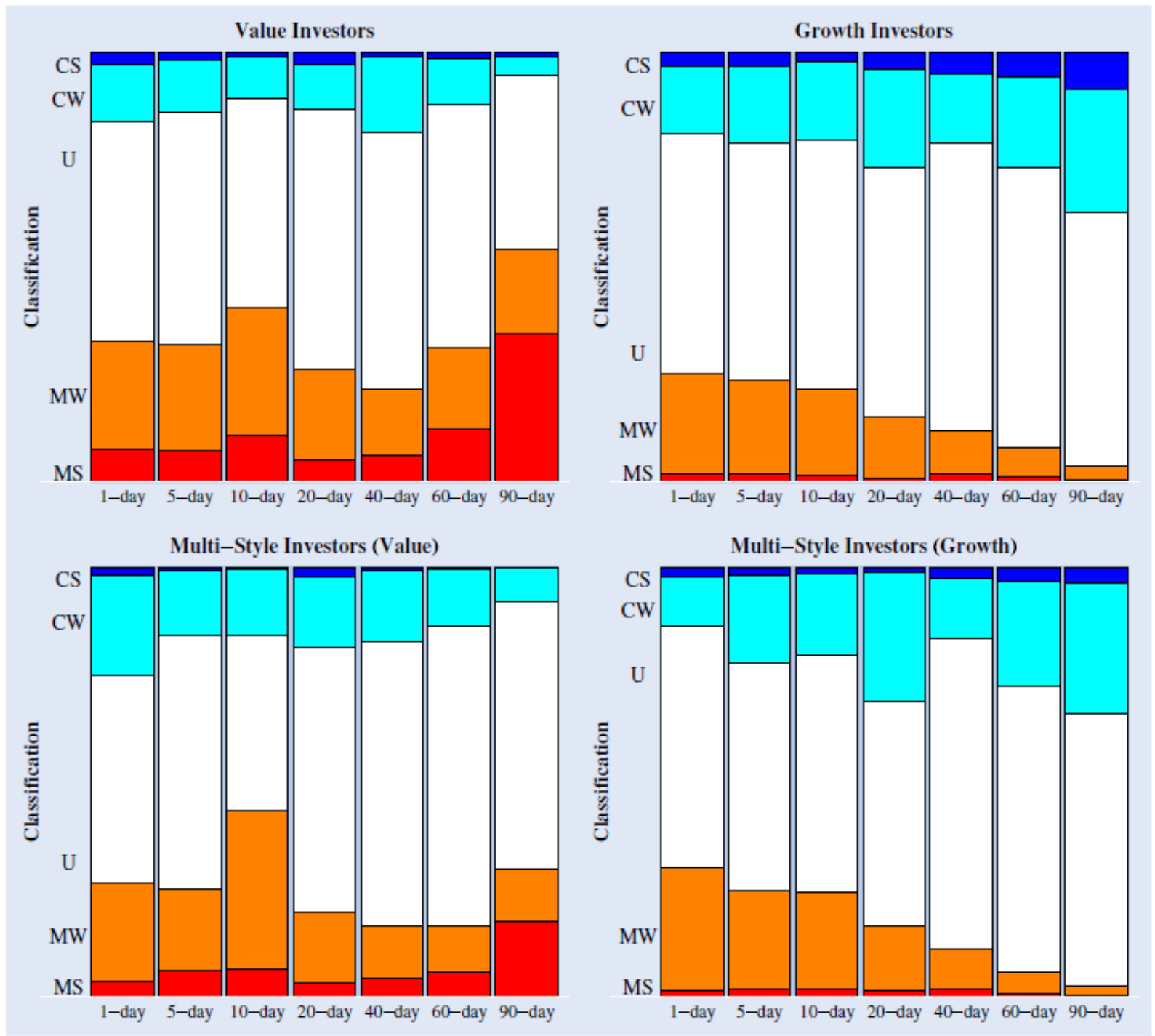

Fig 4. Investor types and return signal-Sells. The chart in each panel shows the distribution of different investors for various past return signals. We classify value investors, growth investors, and multi-style investors who trade in value and in growth funds as being momentum sellers, contrarian sellers and undefined. The categories on the $\mathrm{X}$-axis correspond to the different lengths of the prior return signal, from the return over the previous one day (1-day), five trading days (5-day) —a week, through the return over the previous 90 trading days (90-day). The Y-axis is the proportion of investors classified into one of the five categories (from bottom to top): Momentum Strong (MS), Momentum Weak (MW), Unclassified (U), Contrarian Weak (CW), and Contrarian Strong (CS). 